\title{
EPIDEMIOLOGICAL ASPECTS OF CARDIOMETABOLIC RISK
}

\author{
Ph.D. Thesis \\ Doctoral School of Interdisciplinary Medicine \\ University of Szeged \\ Ádám Hulmán, M.Sc. \\ Department of Medical Physics and Informatics \\ University of Szeged
}

Supervisors

Daniel R. Witte, M.D., Ph.D.

Centre de Recherche Public de la Santé, Luxembourg

János Karsai, Ph.D.

Bolyai Institute, University of Szeged

Tibor Nyári, Ph.D.

Department of Medical Physics and Informatics, University of Szeged

Szeged, 2014 


\section{TABLE OF CONTENTS}

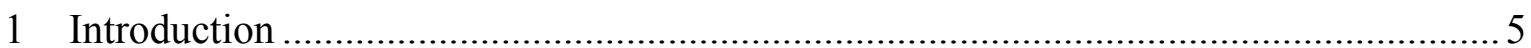

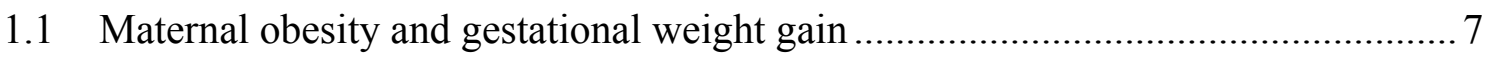

1.2 Secular trends and age-related trajectories of risk factors ................................... 8

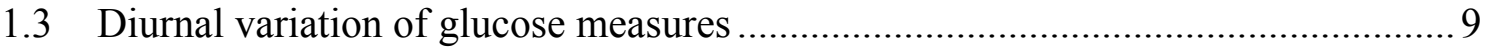

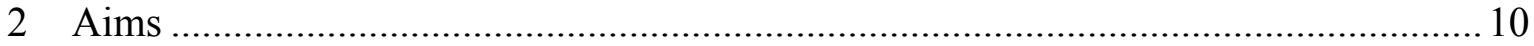

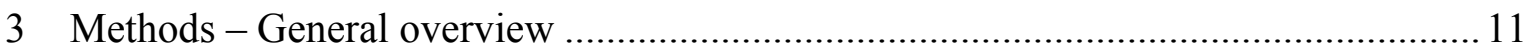

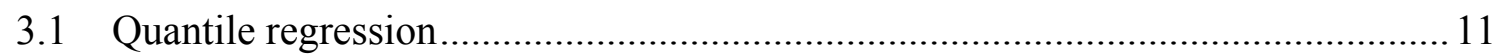

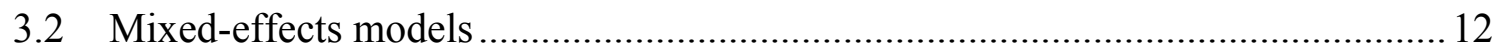

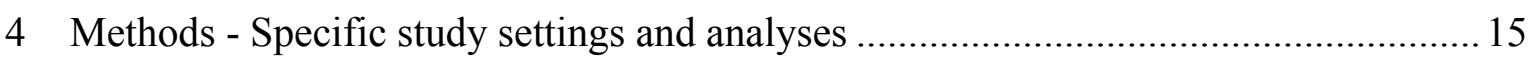

4.1 Maternal obesity and gestational weight gain .................................................. 15

4.1.1 Gestational diabetes screening at the Szent Imre Hospital, Budapest............. 15

4.1.2 Distributional associations of maternal obesity and birthweight .................. 15

4.1.3 Evaluation of hypothetical prevention strategies ......................................... 16

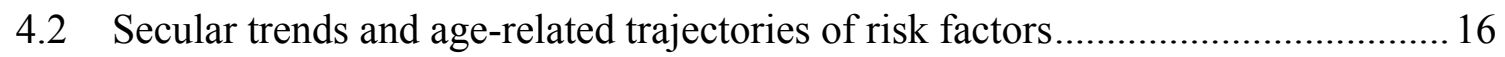

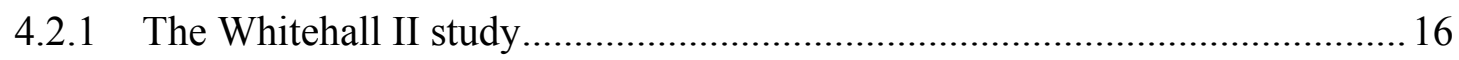

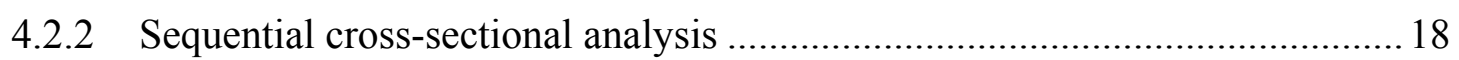

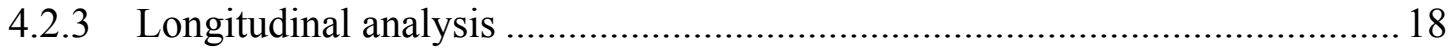

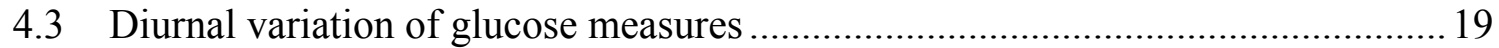

4.3.1 Glucose measures in the Whitehall II study ............................................... 19

4.3.2 Association between fasting status, time of OGTT and glucose measures.... 19

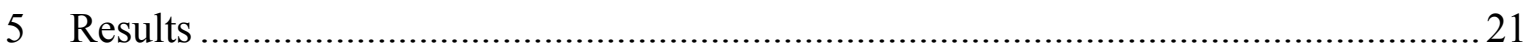

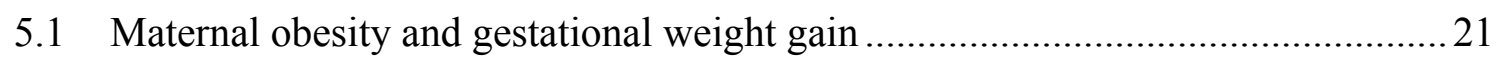

5.2 Secular trends and age-related trajectories of risk factors....................................23

5.2.1 Distributional trends (age group: 57-61 years) …....................................... 23

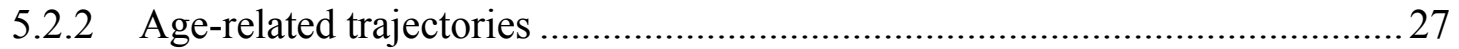

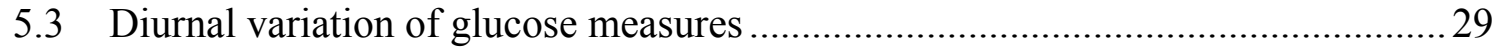

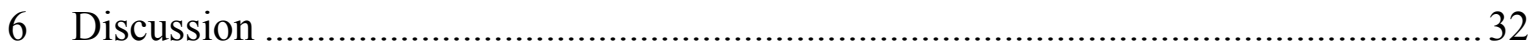

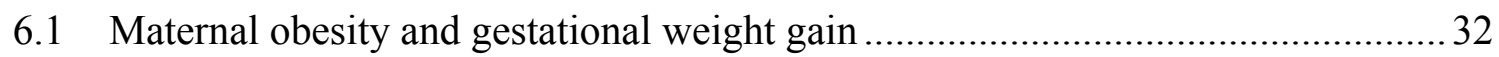

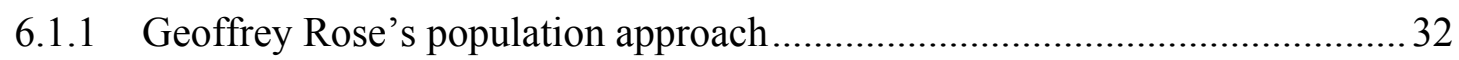

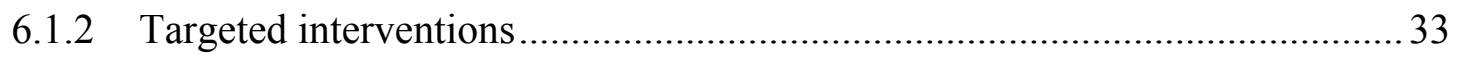

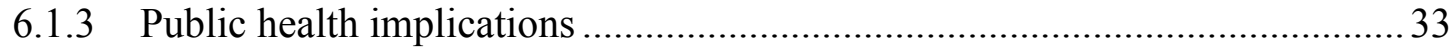




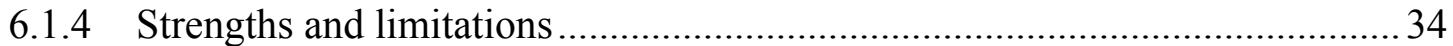

6.2 Secular trends and age-related trajectories of risk factors................................... 34

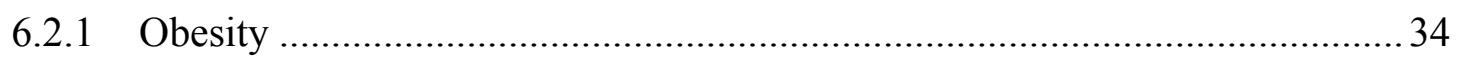

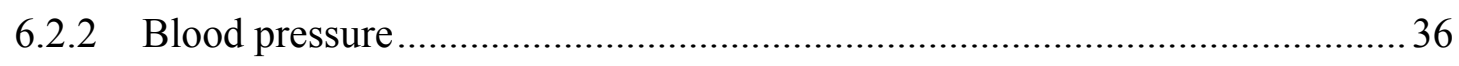

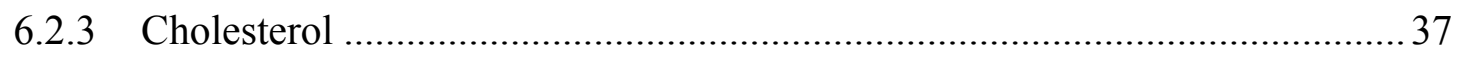

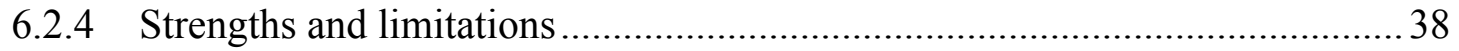

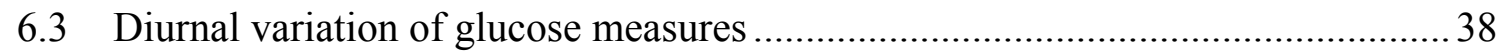

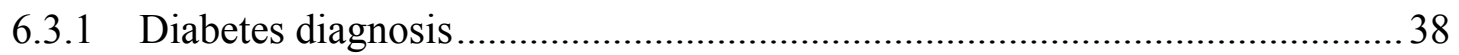

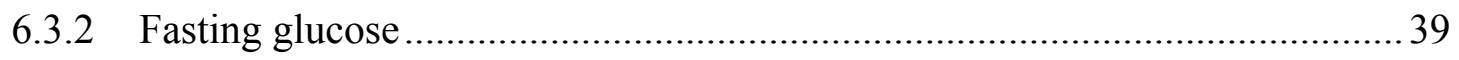

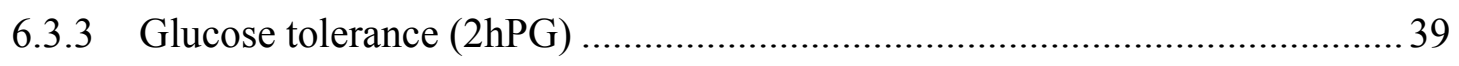

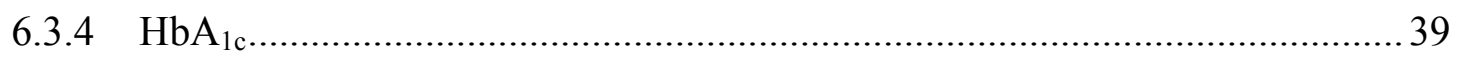

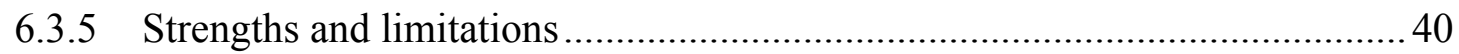

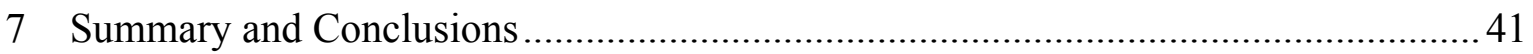

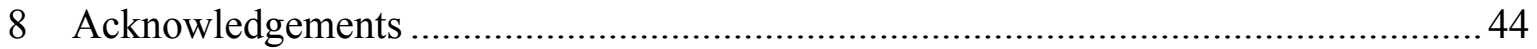

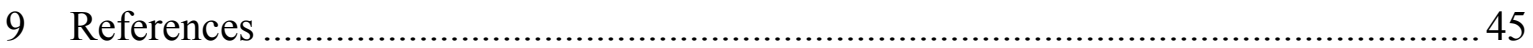




\section{GLOSSARY OF ABBREVIATIONS}

2hPG 2-hour post-load plasma glucose $\quad$ TC $\quad$ Total cholesterol

ADA American Diabetes Association TD Time of day

BMI Body mass index $\quad$ WC Waist circumference

CI Confidence interval WHO World Health Organization

CVD Cardiovascular disease $\quad$ YB $\quad$ Year of birth

DBP Diastolic blood pressure

FD Fasting duration

FPG Fasting plasma glucose

GDM Gestational diabetes mellitus

GWG Gestational weight gain

$\mathrm{HbA}_{1 \mathrm{c}} \quad$ Glycated hemoglobin

HDL High-density lipoprotein

IOM Institute of Medicine

LGA Large for gestational age

MAR Missing at random

MCAR Missing completely at random

MNAR Missing not at random

NCD Non-communicable disease

OLS Ordinary least squares

SBP Systolic blood pressure

SGA Small for gestational age

OGTT Oral glucose tolerance test 


\section{LIST OF PAPERS INCLUDED IN THE THESIS}

I. Hulmán A, Witte DR, Kerényi Zs, Tanczer T, Szabó E, Janicsek Zs, Madarász E, Tabák AG, Nyári TA. Heterogeneous effect of gestational weight gain on birthweight: quantile regression analysis from a population-based screening. (submitted to the Annals of Epidemiology)

II. Hulmán A, Tabák AG, Nyári TA, Vistisen D, Kivimaki M, Brunner EJ, Witte DR. Effect of secular trends on age-related trajectories of cardiovascular risk factors: the Whitehall II longitudinal study 1985-2009. International Journal of Epidemiology 2014; doi:10.1093/ije/dyt279.

III. Hulmán A, Færch K, Vistisen D, Karsai J, Nyári TA, Tabák AG, Brunner EJ, Kivimäki M, Witte DR. Effect of time of day and fasting duration on measures of glycaemia: analysis from the Whitehall II study. Diabetologia 2012;56:294-297. 


\section{INTRODUCTION}

During the second half of the last century, the main focus of epidemiology turned from infectious to non-communicable disease (NCD). According to a WHO report [1], NCD was responsible for $63 \%$ of the 57 million deaths which occurred globally in 2008 . The leading cause among NCD deaths was cardiovascular disease (CVD) with 17 million cases $(48 \%)$, followed by cancer (7.6 million, 21\%), chronic respiratory disease (4.2 million, 12\%) and diabetes with an additional 1.3 million deaths (4\%). Beside premature deaths, morbidity that affects quality of life is also a major component of the burden of NCD. The prevalence of diabetes was about $10 \%$ in 2008 among adults over 25 years of age. People with diabetes have a two- to fourfold risk of CVD compared to those without diabetes. In addition, diabetes is also a leading cause of renal failure, visual impairment and non-traumatic lower limb amputation. The global economic effects of diabetes are also significant. People with diabetes need approximately three times the health-care resources compared to those without diabetes, which added up to $12 \%$ of total health expenditures in 2010 [2].

Overall cardiometabolic risk is determined by various risk factors which play a key role in the pathophysiology which leads to CVD and type 2 diabetes (Figure 1). The four most important modifiable behavioural risk factors include tobacco smoking, sedentary lifestyle, unhealthy diet and excessive alcohol consumption. These lifestyle patterns result in adverse changes in metabolic risk factors, such as obesity, hypertension, hyperglycaemia and dyslipidemia. Non-modifiable risk factors include race, ethnicity, sex, age and family history of diseases. Analysis of cross-sectional data is not sufficient to investigate causality between risk factors and diseases, which points out the importance of prospective studies. The Framingham Heart Study was the first large longitudinal study (initiated in 1948) investigating characteristics of risk factors that lead to CVD. The study played an important role in the identification of risk factors [3]. However, secular trends and changes in diagnostic criteria make it a challenging task to adequately utilize data collected during a long period. 


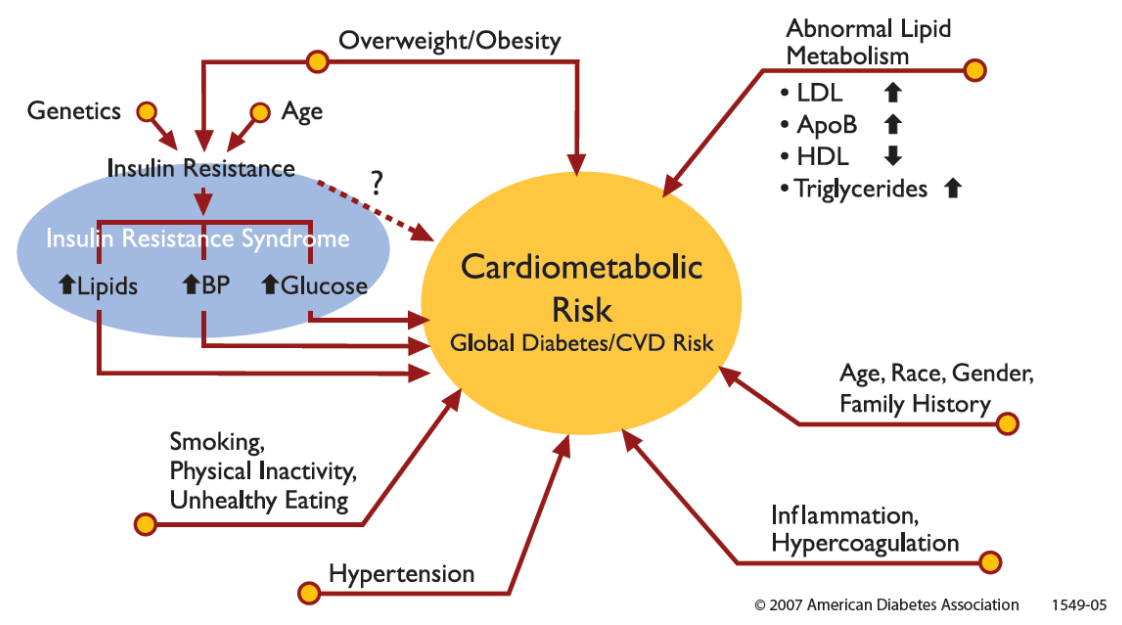

Figure 1 Factors contributing to cardiometabolic risk (source: ADA, CMR Graphic ${ }^{\mathrm{a}}$ )

In 2011, the Global Burden of Metabolic Risk Factors of Chronic Diseases Collaborating Group published four reports in the Lancet on global trends of body mass index (BMI), systolic blood pressure (SBP), total cholesterol (TC) and fasting plasma glucose (FPG) between 1980 and 2008 [4-7]. BMI levels increased globally regardless of economic regions. In contrast, a disparity was observed in the pattern of SBP trends between high- and low-income countries. Favourable trends were seen in western populations, while the opposite was true in Oceania, in East and West Africa, and in South and Southeast Asia. The mean TC level changed little globally, despite marked declines in North America, Europe and Australasia. These favourable trends were counterbalanced by increases in East and Southeast Asia (also in Japan, China and Thailand) and in Pacific subregions. The number of people with diabetes has more than doubled by increasing from 153 million in 1980 to 347 million in 2008, which was driven by a combination of ageing populations due to increasing life expectancy, earlier and more widespread diagnosis of previously undetected cases and increases of obesity and physical inactivity. Prevalence increased by approximately one percentage point (absolute increase) to $9.8 \%$ and $9.2 \%$ in men and women, respectively. Mean FPG increased the most in North America among high-income countries. In 1980, people living in high-income countries had the worst cardiometabolic risk factor profiles, but the heterogeneous trends led to a global convergence of risk factors [8]. Incidence rates for CVD dropped markedly in high-income countries and increased in low- and middle-income countries. The contrasting trends seen

\footnotetext{
${ }^{a}$ link (accessed on March 23, 2014):

http://professional.diabetes.org/ResourcesForProfessionals.aspx?typ=17\&cid=60397\&pcid=60379
} 
in high-income regions suggest that the adverse effects of obesity on blood pressure and cholesterol could be controlled without reversing the obesity epidemic, although also highlight the strong relationship between obesity and diabetes. It also gives the hope and calls for action to prevent a possibly huge burden of CVD and diabetes in developing countries that are experiencing the effects of globalisation and urbanisation similar to those previously seen in western populations. In-depth data collection and novel, sophisticated statistical analyses can help to understand the reasons of contrasting trends in risk factors and to evaluate the effect of potential prevention strategies.

The present thesis examines three different epidemiological aspects of cardiometabolic risk: the effect of maternal obesity and gestational weight gain (GWG) on birthweight; age-related trajectories, secular trends and changing distributions of obesity, blood pressure and cholesterol measures; and diurnal variation of glucose measures and its consequences on diabetes diagnosis.

\subsection{Maternal obesity and gestational weight gain}

The previously mentioned obesity epidemic affects all age groups and women at childbearing age are not exception [9]. Maternal pre-pregnancy BMI and GWG are wellknown determinants of infant birthweight, while both low and high birthweight contribute to the risk of adverse pregnancy outcomes and later health problems in offspring. Women with adverse BMI values (underweight, overweight and obese) have an increased risk of preterm birth and underweight women are more likely to give birth to low birthweight infants [10]. On the high end of the BMI distribution, a recent meta-analysis showed that the beneficial effect of maternal overweight and obesity on low birthweight seems to disappear after adjustment for publication bias [11]. Obese women are also at an increased risk of gestational diabetes, preeclampsia, and having a macrosomic infant [12]. GWG is known to be a modifiable risk factor that is associated with birthweight, independently from maternal BMI. This offers an opportunity to counterbalance the negative effects of too low or high pre-pregnancy BMI by optimizing GWG. Current recommendations from the Institute of Medicine (IOM) reflect the premise that a larger GWG is acceptable in underweight women to prevent small for gestational age (SGA) newborns, while only a limited weight gain is desirable in obese women to reduce the risk of large for gestational age (LGA) newborns $[13,14]$. However, current knowledge and recommendations are 
based on ordinary least squares (OLS) and logistic regression models that lack detail about associations along entire distributions of the continuous outcome variable birthweight. This aspect is especially important when analysing determinants of birthweight, when both ends of the distribution increase the risk of adverse health outcomes. Therefore, a prevention strategy that decreases the variation and kurtosis ${ }^{\mathrm{a}}$ of birthweight is preferable compared to a strategy that induces a left-shift of the entire birthweight distribution.

\subsection{Secular trends and age-related trajectories of risk factors}

Assessment of age-related risk factor trajectories is an important task for epidemiologists from a public health perspective. Knowing the natural progression of risk with ageing might help to identify age groups and individuals that should be targeted more intensely with prevention strategies. Divergence of an individual's risk factor trajectory from the population mean might be a signal of a worsening cardiometabolic risk profile. Although, with mobile devices in the era of information technology, it has never been easier to collect repeated measurements from individuals, most of the current CVD risk calculators use a single measurement in time.

Our current knowledge on the age-related progression of cardiometabolic risk factors is often still based on analyses comparing mean values in different age groups. Such studies cannot capture within-individual changes and might be strongly affected by cohort effects. Cohort effects are generated by the interaction of age and period effects [15]. These population-wide changes (period effects) find people at different times of their life-course, therefore their long-term influence on health might vary between birth cohorts. The last few decades brought marked changes in cardiometabolic risk, which makes the analysis of age-related trajectories especially challenging. Changes of mean levels give only a limited description of secular trends, while changes in risk factor distributions still receive little attention. This issue may have important practical implications because the Rose prevention paradigm, that has strongly affected public health policy in the past decades, assumes that as populations move towards higher CVD risk levels, risk factor distributions shift in their entirety to the unfavourable direction [16-18]. Hence, prevention of CVD events should target entire populations. However, few studies have examined whether changes of risk factor distribution in fact follow this assumption. Most of the

\footnotetext{
a kurtosis measures the "fatness" of a distribution's tails
} 
evidence is on BMI, suggesting that distributions have become increasingly right-skewed in the past decades $[19,20]$, with little right shift of the entire curve. Nevertheless, distributions of other risk factors were rarely analysed simultaneously [21].

\subsection{Diurnal variation of glucose measures}

The consequences of a diabetes diagnosis are lifelong and therefore a diagnosis should be made carefully. Current diagnostic criteria are based on threshold values of blood glucose measures that "distinguish a group with significantly increased premature mortality and increased risk of microvascular and cardiovascular complications" [22]. A WHO expert consultation held in 2009 recommended that an $\mathrm{HbA}_{1 \mathrm{c}}$ measure of $6.5 \%$ or higher should be added to the existing diagnostic criteria (FPG $\geq 7.0 \mathrm{mmol} / \mathrm{L}$ or 2 -h postload plasma glucose $(2 \mathrm{hPG}) \geq 11.1 \mathrm{mmol} / \mathrm{L})$ [23]. Until then, $\mathrm{HbA}_{1 \mathrm{c}}$ was rather used only for the assessment of glycaemic control in people with diabetes, because of standardisation issues, limited availability and influencing factors (e.g. anaemia) [24].

Diurnal variation of glucose tolerance was described more than 40 years ago [2527]. These studies found higher glucose values after an oral glucose tolerance test (OGTT) when measured in the afternoon rather than in the morning. The limitation of the results were the small sample size or/and that time was recorded as a categorical variable (morning versus afternoon). More recent studies focused on fasting glucose [28-30]. To our best knowledge, none of the studies analysed the combined effect of time of day and fasting duration on all three glucose measures.

Recommendations regarding the time of an OGTT and fasting duration according to a WHO Report include the following: "The OGTT should be administered in the morning after at least three days of unrestricted diet (greater than $150 \mathrm{~g}$ of carbohydrate daily) and usual physical activity. ... The test should be preceded by an overnight fast of 814 hours, during which water may be drunk." [31]. The given conditions regarding timing are very permissive and previous evidence suggests that even if following them, measures can vary by time of day and fasting duration. Therefore we hypothetized that there may be remaining heterogeneity in the results of OGTTs even if they are performed according to the current instructions, and that the magnitude of this heterogeneity has the potential to affect the number of diabetes diagnoses in large epidemiological studies. 


\section{AIMS}

The general purpose of the studies included in the thesis was to reveal complex associations and features related to cardiometabolic risk factors and their distributions on a population level that cannot be described adequately with conventional statistical methods. Therefore, we applied sophisticated methodologies to analyse data from relatively large epidemiological studies. The studies included in this thesis investigate cardiometabolic risk from three different epidemiological perspectives. The specific aims of the studies were the following:

- To characterise the effect of pre-pregnancy BMI and maximal GWG on the entire distribution of birthweight, and not only on its mean value. We also wanted to compare how a hypothetical population-based and a high-risk intervention strategy promoting a more modest GWG would perform in the prevention of low birthweight and macrosomia.

- To investigate how secular trends affected cardiometabolic risk factor distributions (e.g. location shift or changing skewness) in the last three decades by applying non-parametric statistical methods. We also aimed to examine agerelated risk factor trajectories and how these were affected by secular trends.

- To explore the individual and the joint effect of time of day and fasting duration on FPG, $2 \mathrm{hPG}$ and $\mathrm{HbA}_{1 \mathrm{c}}$ and to assess whether these associations are affected by ageing and obesity. We also aimed to evaluate the effect of timing on the incidence of diabetes in a large occupational cohort study. 


\section{METHODS - GENERAL OVERVIEW}

This section gives a brief introduction to quantile regression and to mixed-effects models. These two methods are not commonly used in epidemiology and have a key role in this thesis.

\subsection{Quantile regression}

Ordinary least squares (OLS) regression is probably one of the most often used biostatistical method in epidemiology. The interpretation of its results is straightforward: regression coefficients represent the difference in the mean value of the outcome per unit difference in explanatory variables. This simplicity comes with a price, that was first phrased by Mosteller and Tukey in the 1970's [32]:

"What the regression curve does is give a grand summary for the averages of the distributions corresponding to the set of x's. We could go further and compute several different regression curves corresponding to the various percentage points of the distributions and thus get a more complete picture of the set. Ordinarily this is not done, and so regression often gives a rather incomplete picture. Just as the mean gives an incomplete picture of a single distribution, so the regression curve gives a corresponding incomplete picture for a set of distributions." Mosteller, Tukey (1977)

By using OLS linear regression, we can only make statements about how changes in explanatory factors shift the mean of the outcome's distribution [33]. In case of a dichotomised outcome variable (based on a threshold value of a continuous variable), logistic regression reveals changes in a particular part of the distribution without regard to the rest of the distribution. In contrast, quantile regression can shed light on associations at any given point of the outcome's distribution (defined by its quantile), not only on the mean or specific parts based on threshold values. Coefficients from a quantile regression e.g. for the 50th percentile are interpreted similarly to OLS regression, with the exception that they do not represent differences in the mean, but in the 50th percentile. By fitting the same regression model for various quantiles/percentiles, we can get a picture of the explanatory variable's effect on the entire distribution of an outcome. If a population-wide change in an explanatory variable shifts the entire outcome distribution, we expect to see 
very similar (constant) regression coefficients along the percentiles of the outcome. In contrast, if the shape (skewness, kurtosis) of the outcome distribution is also affected, coefficients will vary systematically by percentiles. This heterogeneity of effect sizes cannot be described with regression models focusing on the mean.

Quantile regression was developed and then used in econometrics since the late 1970s [34, 35]. The literature of its applications in epidemiology are very limited, although there seems to be an increase in the last few years. The lack of appropriate software not limit its application, as packages for fitting quantile regression are available in the most commonly used statistical software. In the quantile analyses of this thesis, the quantreg package (version 4.97) was used in the $\mathrm{R}$ language ( $\mathrm{R}$ Foundation for Statistical Computing, Vienna, Austria) [36]. The exact mathematical description of model fitting is beyond the scope of the thesis and is described elsewhere [34].

\subsection{Mixed-effects models}

Until the early 1980's when the first adequate models were developed, there had been a debate on whether change should be measured longitudinally and could be analysed appropriately [37]. The use of OLS regression and cross-sectional data are not sufficient, because it is impossible to separate true change from cohort and period effects. A mixedeffects model can be regarded as an extension of a classical regression model that contains both fixed and random effects. Some variants of mixed-effects models are also known as multilevel models when analysing data with a hierarchical or nested structure. Probably the most common application of such models in epidemiological studies is the analysis of change over time based on repeated measures data. In this case, measurements are nested within individuals, which induces a special correlation structure in the data that cannot be dealt with using classical regression methods. The formulation of an unconditional growth model is shown in Table 1 using labeling conventions from Willett \& Singer [37]. Random effects $\left(\zeta_{0 i}, \zeta_{1 i}\right)$ are introduced to the models to allow varying parameters (e.g. intercept, slope) between individuals. 
Table 1 General formulation of a mixed-effects (multilevel) model.

Level-1 equation
$\begin{gathered}y_{i j}=\pi_{0 i}+\pi_{1 i} \cdot t i m e_{i j}+\varepsilon_{i j} \\ \text { Level-2 equations } \\ \pi_{0 i}=\gamma_{00}+\zeta_{0 i} \\ \pi_{1 i}=\gamma_{10}+\zeta_{1 i}\end{gathered}$
$y_{i j}:$ outcome at time $\mathrm{j}$ of individual i
$\pi_{0 i}, \pi_{1 i}:$ intercept and slope for individual i
time $e_{i j}:$ time of jth measurement of individual i
$\varepsilon_{i j}:$ random measurement error at time $\mathrm{j}$ of individual i
$\gamma_{00}, \gamma_{10}:$ population average of intercept and slope (fixed effects)
$\zeta_{0 i}, \zeta_{1 i}:$ deviations of individual parameters (intercept and slope) from population
averages (random effects)

The level-1 equation specifies the pattern of within-individual change (linear trajectory in this example), whereas the level-2 equations are responsible for the interindividual differences in change. Willet \& Singer phrase the main questions for longitudinal analyses of change that correspond to the two levels: (1) "How does the outcome change over time?" and (2) “Can we predict differences in these changes?”.

Mixed-effects models do not only extend classical regression methods, but also offer some advantages over classical statistical methods for repeated measures (e.g. repeated measures analysis of variance). Both time-varying and time-invariant predictors can be included in the models, which is a common approach in epidemiology to adjust for confounders. Mixed-effects models do not require that measurements are equally spaced in time. They are also flexible by allowing a varying number of measurements per individuals. Because model fitting is likelihood-based, mixed-effects models give valid estimates if data is missing completely at random (MCAR) or missing at random (MAR) [38]. If data is missing not at random (MNAR), sensitivity analyses should be conducted. Unfortunately, there is no hypothesis test to decide which missingness pattern is present.

Data for cross-sectional analyses are usually stored in a "person-level" format, where one record (row) belongs to each individual. When analysing longitudinal data with 
mixed-effects model, a "person-period" data format is used, where each measurement occasion is organised into a separate record. Most of the commonly used statistical software provides functionality to do this data transformation. In the analyses of this thesis, models were fitted with the lme4 package (version 0.99) in the R statistical computing environment [39]. Figures of trajectories and distributions were created in Wolfram Mathematica 9 (Wolfram Research, Champaign, IL, USA). 


\section{METHODS - SPECIFIC STUDY SETTINGS AND ANALYSES}

\subsection{Maternal obesity and gestational weight gain}

\subsubsection{Gestational diabetes screening at the Szent Imre Hospital, Budapest}

In this study, we analysed data from a population-based gestational diabetes mellitus (GDM) screening conducted at the Szent Imre Teaching Hospital between 2002 and 2005 in Budapest, Hungary. The screening program was supported by the Hungarian Medical Research Council (ETT 254/2000) and approved by the Szent Imre Hospital's Ethics Committee. The hospital serves a rather affluent, urbanised population of 200,000. Altogether, 5,335 pregnancies were registered during the study period. After excluding twin pregnancies $(n=122)$, stillbirths $(n=19)$ and records with missing birthweight values $(n=19)$ or other covariates $(n=250)$, the final dataset included 4,925 cases $(92 \%$ of all pregnancies). Data on covariates and outcomes were collected with questionnaires at the time of the OGTT between week 22 and 30 of gestation, immediately after delivery or were extracted from hospital records. Maternal age, ethnicity, education, smoking status, parity, pre-pregnancy weight, maximal GWG and treatment for GDM were recorded. Gestational age was based on the date of the last menstrual period and an ultrasound examination during the first trimester. Height was measured by a trained nurse. BMI was calculated as the ratio of pre-pregnancy weight (in $\mathrm{kg}$ ) and the square of height (in $\mathrm{m}^{2}$ ). Infants' birthweight and sex were extracted from hospital documentation. Low birthweight and macrosomia were defined using the $2500 \mathrm{~g}$ and $4000 \mathrm{~g}$ cut-offs, respectively. A more detailed description of the study procedures is available elsewhere [40].

\subsubsection{Distributional associations of maternal obesity and birthweight}

We analysed the BMI-birthweight and the GWG-birthweight associations with multivariable quantile regression. Models were fitted for the 5th, 15th, ... and 95th percentiles of the outcome (birthweight) distribution. Models were mutually adjusted for BMI and GWG. We further investigated the modifying effect of BMI on the GWGbirthweight association by including the $\mathrm{BMI} \times \mathrm{GWG}$ interaction in the models. All analyses were adjusted for week of delivery, infant's sex, maternal education, ethnicity, age, height, smoking status, parity and interventions (diet or insulin treatment) during pregnancy. Classical regression models were also fitted with exactly the same variables, so that we could compare the results of the two different methods. 


\subsubsection{Evaluation of hypothetical prevention strategies}

We estimated the effect of a hypothetical population-based (-2 kg GWG among all women) and a high-risk (-3 kg GWG among overweight and obese women) prevention strategy by utilising coefficient estimates from the quantile regression models. The birthweight distribution was divided into 10 intervals by the deciles. Each of the previously defined 10 quantile regression models corresponded to one of these intervals (e.g. regression for the 35 th percentile of birthweight belongs to the interval between the 30th and 40th percentile). Therefore we could account for the heterogeneity of associations by estimating birthweights after the hypothetical prevention strategies using coefficient estimates from the specific corresponding quantile regression models (Table 2). The proportion of low birthweight and macrosomic infants, and the standard deviation (SD) of birthweight (a measure of dispersion of the outcome) were calculated from the new hypothetical birthweight distribution. These efficacy measures were based on nonparametric smooth kernel distributions to avoid inconsistency of definitions in the literature (e.g. $>4000 \mathrm{~g}$ and $\geq 4000 \mathrm{~g}$ for macrosomia etc.) and inaccuracy introduced by rounding birthweights.

Table 2 Calculation of birthweights after a hypothetical prevention strategy.

\begin{tabular}{|c|}
\hline$B W_{\text {after }}=B W_{\text {actual }}-D \cdot\left(\operatorname{Coef}_{G W G, i}+\operatorname{Coef}_{G W G \times B M I, i} \cdot B M I\right)$ \\
\hline$B W_{\text {after }}$ : birthweight following a given hypothetical intervention \\
\hline$B W_{\text {actual }}:$ original birthweight \\
\hline $\begin{array}{l}D: \text { GWG decrease according to the strategy (population-based: } 2 \mathrm{~kg} \text {; high-risk: } 3 \\
\mathrm{~kg} \text { if overweight or obese, } 0 \mathrm{~kg} \text { otherwise) }\end{array}$ \\
\hline $\begin{array}{l}\operatorname{Coef}_{G W G, i}, \text { Coef }_{G W G \times B M I, i} \text { : coefficients of GWG and GWG } \times \text { BMI from the quantile } \\
\text { regression at the location of birthweight in the distribution (in the ith interval) }\end{array}$ \\
\hline$B M I$ : maternal pre-pregnancy body mass index \\
\hline
\end{tabular}

\subsection{Secular trends and age-related trajectories of risk factors}

\subsubsection{The Whitehall II study}

The Whitehall II study is an occupational cohort of British civil servants, set up 30 years ago to investigate social and occupational differences in health and disease [41]. Cardiovascular disease and diabetes played an important role in the scientific contributions of the study [42-44]. 
Between 1985 and 1988, 10,308 men and women (73\% of those invited), aged 3555 years and employed in London-based government departments, participated in the first phase of the Whitehall II study. Participants differed widely in employment level from clerical to senior administrative grades. Two thirds of them were men. Clinical examinations in addition to postal questionnaires were part of every second phase, i.e. phase 1 in 1985-88, phase 3 in 1991-94, phase 5 in 1997-99, phase 7 in 2002-04 and phase 9 in 2007-09, when the entire cohort was invited to the research clinic. This resulted in up to five repeated measurements per individuals. The University College London ethics committee reviewed and approved the study. Written informed consent was obtained from all participants at each study phase. The exact number of participants at each phase is displayed in Table 3. The attrition rate was the highest between phase 1 and 3 with $13 \%$. Loss to follow-up because of non-response or death until phase 9 was $31 \%$ and $41 \%$ among men and women, respectively.

Table 3 Summary of participation status at each study phase. Number of participants and cumulative number of deaths and non-responses are reported.

\begin{tabular}{llllll}
\hline & $\begin{array}{l}\text { Phase 1 } \\
\text { 1985-1988 }\end{array}$ & $\begin{array}{l}\text { Phase 3 } \\
1991-1994\end{array}$ & $\begin{array}{l}\text { Phase 5 } \\
1997-1999\end{array}$ & $\begin{array}{l}\text { Phase 7 } \\
\text { 2002-2004 }\end{array}$ & $\begin{array}{l}\text { Phase 9 } \\
\text { 2007-2009 }\end{array}$ \\
\hline $\begin{array}{l}\text { Men } \\
\text { Participated }\end{array}$ & 6895 & 6057 & 5473 & 4893 & 4759 \\
$\begin{array}{l}\text { Died } \\
\text { Non-response }\end{array}$ & & 81 & 204 & 389 & 621 \\
Women & & 757 & 1218 & 1613 & $1515^{\mathrm{a}}$ \\
$\begin{array}{l}\text { Participated } \\
\text { Died }\end{array}$ & 3413 & 2758 & 2397 & 2074 & 2002 \\
Non-response & & 44 & 102 & 195 & 333 \\
\hline
\end{tabular}

${ }^{a}$ Cumulative numbers may decrease, because we had information about the death of participants, even if they did not respond in a previous phase.

Anthropometric measures were assessed by trained research nurses according to standardised protocols. Waist circumference (WC) was first measured in phase 3, when the smallest value was recorded below the costal margin. SBP and diastolic blood pressure (DBP) were measured twice in a seated posture after a minimum of 5 minutes rest, and the average values were used in the analyses. A manual random zero sphygmomanometer (MRZ) was used in phases 3 and 5, and an automated oscillometric device (AOD) in phases 7 and 9. Further details on blood pressure measures can be found in [45]. The 
biochemical analysis of blood samples to assess TC and high-density lipoprotein (HDL) cholesterol values is described in details elsewhere [46].

\subsubsection{Sequential cross-sectional analysis}

Secular trends were first investigated in a subgroup of participants aged 57-61 (to exclude the effect of ageing) with sequential cross-sectional analyses stratified by sex. This age group was not represented at phase 1, when participants were at 35-55 years of age, so the study period for this analysis was 18-year long (1991-2009). We first described changes in BMI, WC, SBP, DBP, TC and HDL by calculating the 10th, 50th and 90th percentiles at each phase. Linear trends were estimated for these specific percentiles with quantile regression models using calendar year as the explanatory variable. We kept calendar year as a continuous rather than a categorical variable, as study phases were normally 2-3 years long providing more values in the valid range. Non-parametric smooth kernel distributions (using Gaussian kernels) were fitted to the data to get an overall picture of distributional changes (location and shape) between phases.

\subsubsection{Longitudinal analysis}

Quadratic age-related risk factor trajectories for the mean were assessed by fitting mixed-effects models with random intercepts for the entire Whitehall II cohort, stratified by sex. Year of birth and its interaction terms with age and age-squared were included in the models to investigate secular trends and cohort effects (Table 4). Using these model terms, we could account for possible differences in trajectory characteristics (level and curvature) between birth cohorts. We conducted sensitivity analyses to investigate the possible impact of data being MNAR. The models described above were fitted to a relatively healthier subgroup of participants who participated up to phase 9 (not necessarily in each phase until then) to test the robustness of our results against selective loss of follow-up and healthy survival. 
Table 4 Model form of age-related trajectories.

$\quad R F=$ Coef $_{\text {Intercept }}+\left(\right.$ Coef $_{\text {Age }}+$ Coef $\left._{Y B \times A g e} \cdot Y B\right) \cdot$ Age $+\left(\right.$ Coef $_{\text {Age }^{2}}+$ Coef $\left._{Y B \times A g e^{2}} \cdot Y B\right) \cdot$ Age $^{2}$
$R F:$ risk factor $(\mathrm{BMI}, \mathrm{WC}, \mathrm{SBP}, \mathrm{DBP}, \mathrm{TC}, \mathrm{HDL})$
Coef... estimated model coefficients
$Y B:$ year of birth
Age $:$ age

\subsection{Diurnal variation of glucose measures}

\subsubsection{Glucose measures in the Whitehall II study}

We analysed data from the Whitehall II study, which was previously described. FPG and 2hPG measures were assessed with a 75-g OGTT with glucose measurements at 0 and 120 minutes (starting times between 08:00 and 15:00 hours) that was part of the clinical examination from phase 3 onward. $\mathrm{HbA}_{1 \mathrm{c}}$ was measured in phases 7 and 9. Blood samples were handled according to standard protocols: samples were drawn into fluoride monovette tubes (to prevent glycolysis), which were centrifuged on site within 1 hour. Plasma was transferred into microtubes immediately after centrifugation and stored at $-70{ }^{\circ} \mathrm{C}$. The biochemical analysis to assess FPG, $2 \mathrm{hPG}$ and $\mathrm{HbA}_{1 \mathrm{c}}$ values is described in details elsewhere [42]. Time of fasting blood draw was recorded by a trained nurse as HH:MM on the participant's clinical report form based on a standardised clock in the examination room. Fasting duration was calculated from the time of the last meal, which was self-reported. Participants of white ethnicity and with valid glucose measures were considered in this analysis. Person-examinations were excluded because of the following reasons: participant was previously diagnosed with diabetes or was currently on glucoselowering treatment $(n=1,266)$, unrealistic fasting duration (last meal before 17:00 hours on the previous day or after 01:00 hours on the day of the OGTT, n=334) or missing contemporary anthropometric measures $(n=407)$. The final dataset included 5,978 participants (with 13,269 person-examinations) of white ethnicity, from 40 to 80 years of age.

\subsubsection{Association between fasting status, time of OGTT and glucose measures}

The effect of time of day and fasting duration on glucose measures (FPG, 2hPG and $\mathrm{HbA}_{1 \mathrm{c}}$ ) was assessed with age- and $\mathrm{BMI}$-adjusted mixed-effects models that were 
stratified by sex. Models with $2 \mathrm{hPG}$ as outcome variable included further adjustment for height, as previously suggested [47]. All models were adjusted for study phase (included as a categorical variable) to model potential phase-specific, systematic differences in measurements. To handle the within-person correlation arising from the longitudinal structure of the data, random effects for the intercept were included in the models. We also fitted all models with standardised outcomes to investigate the relative effect of timing factors on glucose measures. After the individual effect of time of day and fasting duration had been examined, all models were fitted with both variables at the same time. Deviancebased hypothesis tests were used to investigate whether this improved model fit. The effect of ageing and BMI on diurnal variation was analysed by including the appropriate interaction terms in the models. 


\section{RESULTS}

\subsection{Maternal obesity and gestational weight gain}

General characteristics of the study population are displayed in Table 5. Participants were relatively lean with a mean BMI of $22.7 \pm 4.1 \mathrm{~kg} / \mathrm{m}^{2}$ and low prevalence of overweight (15\%) and obesity (6\%). They were predominantly Caucasian (98\%) and abstained from smoking during pregnancy (95\%). Almost $90 \%$ of participants finished at least high school.

Table 5 Characteristics of study population from the GDM in Budapest (2002-2005).

\begin{tabular}{lcc}
\hline \multicolumn{1}{l}{$\%$} & Mean \pm SD (Q1-Q3) \\
\hline Maternal & & $29.3 \pm 4.3(27-32)$ \\
Age (years) & 98.1 & \\
Caucasian (\%) & & \\
Education (\%) & 12.7 & \\
$\quad$ Less than high school & 39.2 & \\
$\quad$ High school & 48.1 & \\
$\quad$ College & & \\
Parity (\%) & 55.1 & \\
0 & 41.0 & \\
$1-2$ & 3.9 & \\
$\geq 3$ & & \\
Intervention (\%) & 93.5 & \\
$\quad$ None & 5.1 & \\
Diet & 1.4 & \\
$\quad$ Insulin treatment & 5.2 & \\
Any smoking during pregnancy (\%) & & $166.5 \pm 6.4(163-170)$ \\
Height (cm) & & $22.7 \pm 4.1(20.0-24.3)$ \\
Pre-pregnancy BMI (kg/m $\left.{ }^{2}\right)$ & & \\
Gestational weight gain (kg) & & $39.1 \pm 1.9(39-40)$ \\
Newborn & & $3,446 \pm 465(3,150-3,750)$ \\
Gestational age at delivery (weeks) & & \\
Birthweight (g) & & \\
Male sex (\%) & &
\end{tabular}

Maternal GWG and pre-pregnancy BMI were both positively associated with birthweight (in a mutually adjusted model). Effect sizes increased towards higher percentiles of the birthweight distribution, especially for pre-pregnancy BMI (Figure 2). 
Classical regression models described the association well only in the middle region of the birthweight distribution.
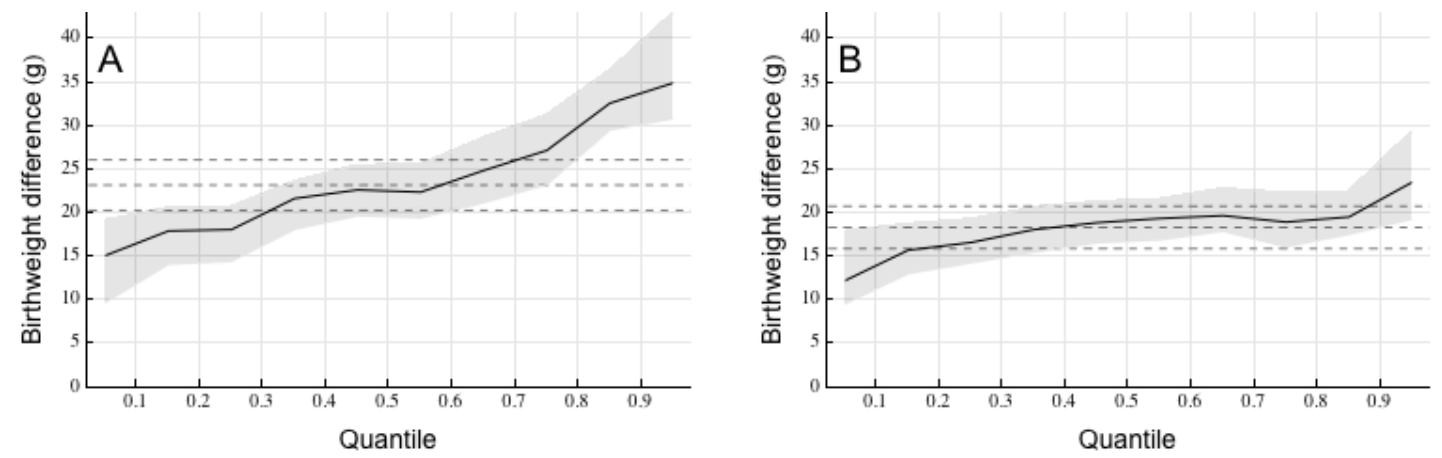

Figure 2 Effect of pre-pregnancy BMI (A) and gestational weight gain (B) on birthweight with 95\% CIs along the birthweight distribution (by quantile) from quantile regression (solid lines) and classical linear regression (dashed lines) models

The effect of GWG on birthweight was modified by pre-pregnancy BMI, which was analysed by adding the $\mathrm{GWG} \times \mathrm{BMI}$ interaction to the previous models. Coefficient estimates for GWG at a BMI of 20 and $30 \mathrm{~kg} / \mathrm{m}^{2}$ are displayed in Figure 3. Estimates from classical linear regression models are displayed with dashed lines. At a pre-pregnancy BMI of $20 \mathrm{~kg} / \mathrm{m}^{2}$, a $1 \mathrm{~kg}$ difference in GWG was associated with a 10.2 [95\% CI: 6.1; 14.5] g and $23.1[17.5 ; 29.0] \mathrm{g}$ higher birthweight at the 5th and 95th percentile of birthweight, respectively. In contrast, at a pre-pregnancy BMI of $30 \mathrm{~kg} / \mathrm{m}^{2}$, we did not observe an increasing trend by quantile in effect sizes, which ranged from 18.6 to $26.0 \mathrm{~g}$ along the birthweight distribution.
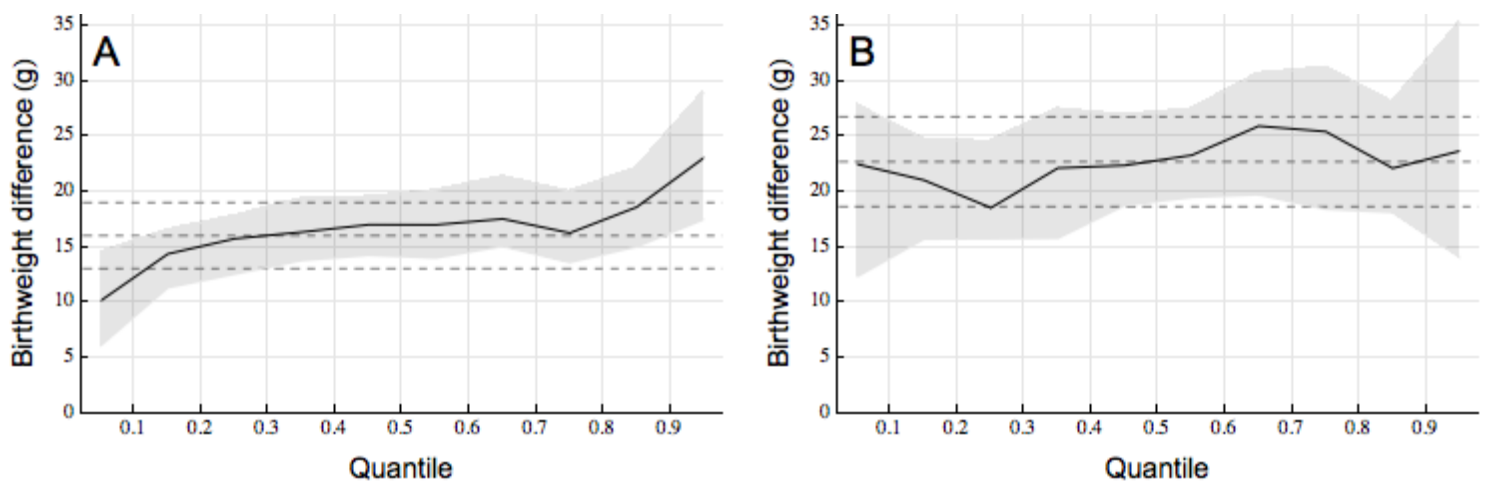

Figure 3 Effect of gestational weight gain on birthweight with $95 \%$ CIs along the birthweight distribution (by quantile) for two different BMI values: $20 \mathrm{~kg} / \mathrm{m}^{2}$ (A) and 30 $\mathrm{kg} / \mathrm{m}^{2}(\mathrm{~B})$, from quantile regression (solid lines) and classical linear regression (dashed lines) models 
The effects of our hypothetical prevention strategies on birthweight related pregnancy outcomes are summarised in Table 6. Calculations based on quantile regression models showed that the relative decrease in the proportion of macrosomic infants $(-15 \%)$ was greater than the increase in low birthweight $(+12 \%)$ after a hypothetical populationbased prevention strategy. Using coefficient estimates from classical regression models resulted the opposite $(-13 \%$ and $+17 \%$, respectively). The high-risk strategy slightly increased the proportion of low birthweight infants, but the presence of macrosomia decreased only by $6 \%$.

Table 6 Efficacy of hypothetical prevention strategies (based on quantile regression coefficients) promoting a more modest gestational weight gain.

\begin{tabular}{lccc}
\hline Prevention strategy & $\begin{array}{c}\text { Macrosomia } \\
\%\end{array}$ & $\begin{array}{c}\text { Low birthweight } \\
\%\end{array}$ & $\begin{array}{c}\text { SD } \\
\mathrm{g}\end{array}$ \\
\hline Observed data & 11.2 & 2.3 & 470 \\
Population-based (-2 kg GWG) & 9.6 & 2.5 & 465 \\
High-risk (-3 kg GWG if BMI $\left.\geq 25 \mathrm{~kg} / \mathrm{m}^{2}\right)$ & 10.5 & 2.3 & 467 \\
\hline
\end{tabular}

Values are based on non-parametric smooth kernel distributions.

\subsection{Secular trends and age-related trajectories of risk factors}

Baseline characteristics of the Whitehall II cohort are shown in Table 7. Women had generally lower employment grades and were more likely to be current smokers than men. WC and HDL cholesterol differed the most between sexes.

\subsubsection{Distributional trends (age group: 57-61 years)}

Risk factor percentiles (10th, 50th, 90th) for phases 3, 5, 7 and 9 and linear trends from quantile regression models are displayed in Table 8. Smooth kernel distributions are shown in Figure 4.

Changes in the BMI distribution of men were characterised by a right-shift of the median and a fattening right tail. Increments were heterogeneous along the distribution and were the largest at the 90th percentile $\left(+2.8 \mathrm{~kg} / \mathrm{m}^{2}\right)$. For women the low BMI segment remained unchanged, but the 90th percentile increased by $2 \mathrm{~kg} / \mathrm{m}^{2}$ leading to a fat tail on the right. 
Table 7 Baseline characteristics of the Whitehall II cohort (1985-1988). Values are medians (Q1-Q3) or percentages.

\begin{tabular}{lll}
\hline & Men $(\mathrm{n}=6,895)$ & Women $(\mathrm{n}=3,413)$ \\
\hline Age (year) & $43(39-49)$ & $45(40-51)$ \\
Whites (\%) & 91.5 & 84.2 \\
Smoking (\%) & & \\
$\quad$ Never & 47.3 & 52.9 \\
Ex & 36.1 & 23.3 \\
Current & 15.8 & 23.3 \\
Missing & 0.8 & 0.5 \\
Grade level (\%) & & \\
Administrative & 38.4 & 11.2 \\
Prof/Executive & 52.3 & 39.1 \\
Clerical/Support & 9.3 & 49.7 \\
\hline BMI (kg/m $\left.{ }^{2}\right)$ & $24.3(22.6-26.2)$ & $24.0(21.9-26.7)$ \\
WC $(\mathrm{cm})$ & $88.9(83.0-94.7)$ & $76.5(69.5-85.4)$ \\
SBP (mmHg) & $123(115-133)$ & $118(109-130)$ \\
DBP (mmHg) & $77(71-84)$ & $75(68-81)$ \\
TC (mmol/l) & $5.9(5.2-6.7)$ & $5.8(5.1-6.6)$ \\
HDL-C (mmol/l) & $1.3(1.1-1.6)$ & $1.6(1.4-2.0)$ \\
\hline
\end{tabular}

${ }^{\mathrm{a}} \mathrm{WC}$ measures are from phase 3 (1991-1994).

In contrast with BMI, WC increased along the entire distribution. The increment was largest at the right end of the distribution $(+8 \mathrm{~cm}$ at the 90 th percentile) in both men and women. The change in SBP was not consistent: it increased until phase 7 and then dropped markedly at phase 9. Therefore the linear trend cannot be interpreted. In contrast the entire DBP distribution shifted to the left by approximately $10 \mathrm{mmHg}$ in both men and women.

The linear trend was of similar magnitude along the entire TC distribution, which led to a left-shift of the distribution with $1.5 \mathrm{mmol} / \mathrm{l}$ in both men and women. Changes in HDL cholesterol were modest compared to TC, although all percentiles increased by 0.1 $0.2 \mathrm{mmol} / 1$. 
Table 8 Secular trends based on percentiles of risk factors in men and women.

\begin{tabular}{|c|c|c|c|c|c|c|}
\hline Men & Percentile & $\begin{array}{l}\text { Phase } 3 \\
\mathrm{n}=911\end{array}$ & $\begin{array}{l}\text { Phase } 5 \\
n=903\end{array}$ & $\begin{array}{l}\text { Phase } 7 \\
n=1,222\end{array}$ & $\begin{array}{l}\text { Phase } 9 \\
n=1,391\end{array}$ & $\begin{array}{l}\text { Linear trend }{ }^{\mathrm{a}} \text { (per year) } \\
\beta[95 \% \mathrm{CI}]\end{array}$ \\
\hline \multirow{3}{*}{$\begin{array}{l}\mathrm{BMI} \\
\left(\mathrm{kg} / \mathrm{m}^{2}\right)\end{array}$} & 10th & 21.9 & 22.2 & 22.4 & 21.9 & $0.004[-0.014 ; 0.027]$ \\
\hline & 50 th & 25.1 & 25.6 & 26.1 & 26.4 & $0.080[0.065 ; 0.096]^{* * *}$ \\
\hline & 90th & 29.1 & 30.4 & 31.8 & 31.9 & $0.192[0.145 ; 0.234]^{* * *}$ \\
\hline \multirow{3}{*}{$\begin{array}{l}\mathrm{WC} \\
(\mathrm{cm})\end{array}$} & 10th & 78.4 & 80.3 & 81.2 & 80.6 & $0.152[0.100 ; 0.210]^{* * *}$ \\
\hline & 50 th & 88.2 & 91.9 & 93.6 & 94.2 & $0.360[0.318 ; 0.409]^{* * *}$ \\
\hline & 90th & 101.4 & 105.2 & 108.4 & 109.6 & $0.508[0.433 ; 0.631]^{* * *}$ \\
\hline \multirow{3}{*}{$\begin{array}{l}\text { SBP } \\
(\mathrm{mmHg})\end{array}$} & 10th & 107 & 106 & 109 & 107 & $0.000[-0.086 ; 0.092]$ \\
\hline & 50 th & 125 & 123 & 126 & 124 & $0.000[-0.031 ; 0.083]$ \\
\hline & 90th & 145 & 148 & 150 & 143 & $-0.181[-0.313 ;-0.030]^{*}$ \\
\hline \multirow{3}{*}{$\begin{array}{l}\mathrm{DBP} \\
(\mathrm{mmHg})\end{array}$} & 10th & 71 & 65 & 61 & 60 & $-0.654[-0.714 ;-0.603]^{* * *}$ \\
\hline & 50 th & 82 & 78 & 75 & 73 & $-0.594[-0.653 ;-0.517]^{* * *}$ \\
\hline & 90th & 95 & 91 & 89 & 85 & $-0.577[-0.650,-0.490]^{* * *}$ \\
\hline \multirow{3}{*}{$\begin{array}{l}\mathrm{TC} \\
(\mathrm{mmol} / \mathrm{l})\end{array}$} & 10th & 5.3 & 4.8 & 4.5 & 4.0 & $-0.079[-0.085 ;-0.074] * * *$ \\
\hline & 50 th & 6.7 & 5.9 & 5.7 & 5.2 & $-0.083[-0.088 ;-0.077]^{* * *}$ \\
\hline & 90th & 8.1 & 7.3 & 7.0 & 6.6 & $-0.086[-0.093 ;-0.079]^{* * *}$ \\
\hline \multirow{3}{*}{$\begin{array}{l}\text { HDL-C } \\
(\mathrm{mmol} / \mathrm{l})\end{array}$} & 10th & 0.9 & 1.0 & 1.0 & 1.0 & $0.005[0.003 ; 0.008]^{* * *}$ \\
\hline & 50 th & 1.3 & 1.3 & 1.4 & 1.4 & $0.008[0.004 ; 0.010]^{* * *}$ \\
\hline & 90th & 1.8 & 1.9 & 1.9 & 2.0 & $0.011[0.009 ; 0.013]^{* * *}$ \\
\hline
\end{tabular}

\begin{tabular}{|c|c|c|c|c|c|c|}
\hline Women & Percentile & $\begin{array}{l}\text { Phase } 3 \\
n=520\end{array}$ & $\begin{array}{l}\text { Phase } 5 \\
n=383\end{array}$ & $\begin{array}{l}\text { Phase } 7 \\
n=492\end{array}$ & $\begin{array}{l}\text { Phase } 9 \\
n=514\end{array}$ & $\begin{array}{l}\text { Linear trend }{ }^{\mathrm{a}} \text { (per year) } \\
\beta[95 \% \mathrm{CI}]\end{array}$ \\
\hline \multirow{3}{*}{$\begin{array}{l}\mathrm{BMI} \\
\left(\mathrm{kg} / \mathrm{m}^{2}\right)\end{array}$} & 10th & 21.3 & 21.2 & 21.2 & 21.1 & $-0.007[-0.043 ; 0.021]$ \\
\hline & 50 th & 26.0 & 25.8 & 25.8 & 26.1 & $0.000[-0.023 ; 0.025]$ \\
\hline & 90th & 32.8 & 32.5 & 33.8 & 34.8 & $0.120[0.063 ; 0.205]^{* *}$ \\
\hline \multirow{3}{*}{$\begin{array}{l}\text { WC } \\
(\mathrm{cm})\end{array}$} & 10th & 64.9 & 68.0 & 68.1 & 69.9 & $0.289[0.190 ; 0.351]^{* * *}$ \\
\hline & 50 th & 78.4 & 80.0 & 81.0 & 83.0 & $0.276[0.173 ; 0.391]^{* * *}$ \\
\hline & 90th & 96.0 & 96.3 & 100.2 & 104.0 & $0.482[0.354 ; 0.657]^{* * *}$ \\
\hline \multirow{3}{*}{$\begin{array}{l}\text { SBP } \\
(\mathrm{mmHg})\end{array}$} & 10th & 104 & 103 & 104 & 99 & $-0.277[-0.406 ;-0.091]^{* *}$ \\
\hline & 50 th & 122 & 123 & 123 & 116 & $-0.350[-0.516 ;-0.202]^{* * *}$ \\
\hline & 90th & 141 & 148 & 147 & 141 & $0.094[-0.141 ; 0.278]$ \\
\hline \multirow{3}{*}{$\begin{array}{l}\mathrm{DBP} \\
(\mathrm{mmHg})\end{array}$} & 10th & 66 & 64 & 60 & 56 & $-0.634[-0.707 ;-0.524]^{* * *}$ \\
\hline & 50 th & 78 & 75 & 72 & 69 & $-0.558[-0.647 ;-0.491]^{* * *}$ \\
\hline & 90th & 90 & 89 & 88 & 84 & $-0.359[-0.464 ;-0.201]^{* * *}$ \\
\hline \multirow{3}{*}{$\begin{array}{l}\mathrm{TC} \\
(\mathrm{mmol} / \mathrm{l})\end{array}$} & 10th & 5.8 & 4.9 & 4.7 & 4.4 & $-0.084[-0.093 ;-0.071]^{* * *}$ \\
\hline & 50 th & 7.0 & 6.1 & 5.9 & 5.5 & $-0.084[-0.093 ;-0.078]^{* * *}$ \\
\hline & 90th & 8.8 & 7.6 & 7.3 & 6.9 & $-0.115[-0.122 ;-0.098]^{* * *}$ \\
\hline \multirow{3}{*}{$\begin{array}{l}\mathrm{HDL}-\mathrm{C} \\
(\mathrm{mmol} / \mathrm{l})\end{array}$} & 10th & 1.2 & 1.2 & 1.3 & 1.3 & $0.009[0.007 ; 0.010]^{* * *}$ \\
\hline & 50 th & 1.6 & 1.6 & 1.8 & 1.8 & $0.012[0.010 ; 0.019]^{* * *}$ \\
\hline & 90th & 2.3 & 2.2 & 2.5 & 2.5 & $0.015[0.011 ; 0.023]^{* * *}$ \\
\hline
\end{tabular}

$* \mathrm{p}<0.05, * * \mathrm{p}<0.01, * * * \mathrm{p}<0.001$

${ }^{a}$ Linear trends were assessed with quantile regression models. 


\section{Men}
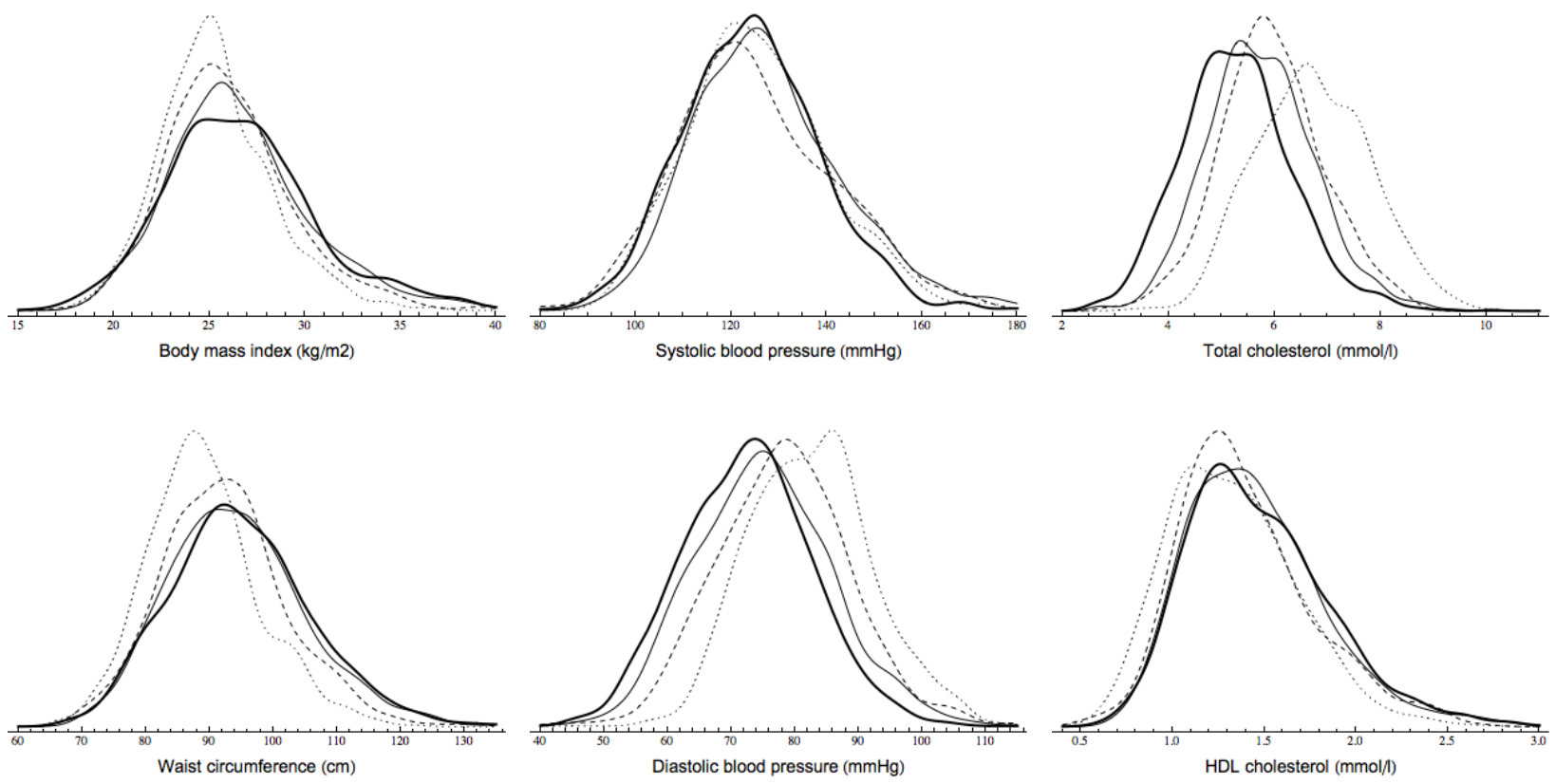

\section{Women}
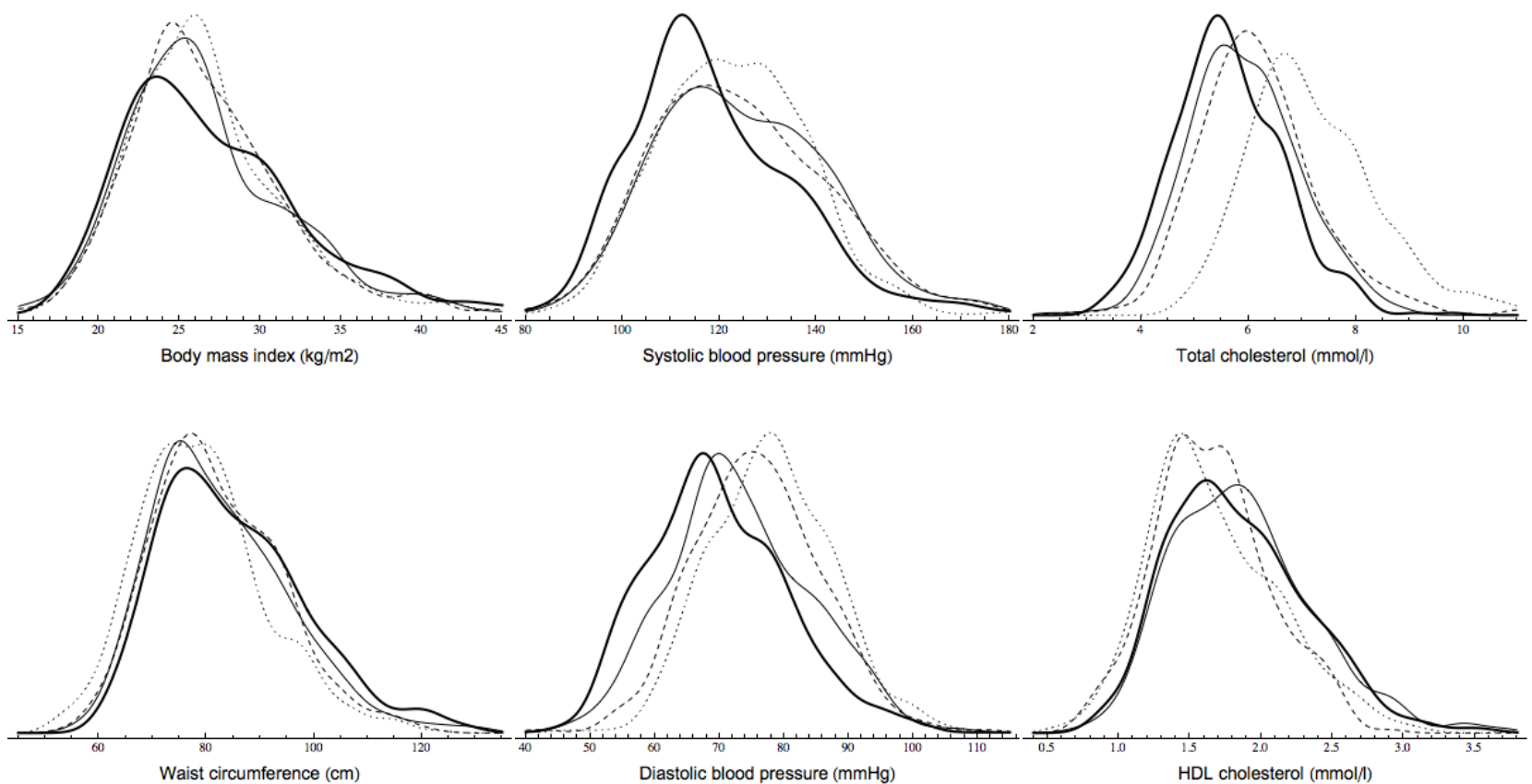

Figure 4 Smooth kernel distributions of risk factors (probability density functions are displayed) in men and women (dotted line: phase 3, dashed line: phase 5, solid line: phase 7, thick line: phase 9) 
Changes in the proportion of smokers and people on either lipid-lowering or antihypertensive treatment are shown in Table 9. Fewer women smoked in the later phases, while the number of smokers among men remained constant around $8 \%$. Both lipidlowering and antihypertensive medication usage increased drastically. Between 2007 and 2009 approximately every fourth person was on treatment in the 57-61 age group.

Table 9 Secular trends of smoking habits, lipid-lowering and antihypertensive medication.

\begin{tabular}{lrrrr}
\hline & Phase 3 & Phase 5 & Phase 7 & Phase 9 \\
\hline Men & & & & \\
Current smoker & 8.5 & 8.8 & 8.7 & 7.9 \\
Lipid treatment & 1.4 & 4.1 & 10.6 & 24.0 \\
Anti-hyp. treatment & 12.4 & 15.2 & 21.9 & 28.0 \\
\hline Women & & & & \\
Current smoker & 15.9 & 10.6 & 11.3 & 4.7 \\
Lipid treatment & 2.0 & 4.1 & 7.9 & 19.9 \\
Anti-hyp. treatment & 16.9 & 20.9 & 20.9 & 24.8 \\
\hline
\end{tabular}

Values are percentages.

\subsubsection{Age-related trajectories}

Age-related trajectories (unadjusted and adjusted for four different year of births) of cardiometabolic risk factors - based on data from the entire Whitehall II cohort - are displayed in Figure 5.

BMI and WC increased faster with age and were at higher levels at any given age in younger birth cohorts than in older. The BMI difference between those born in 1933 and 1948 at age 60 was $1.3[1.1 ; 1.5] \mathrm{kg} / \mathrm{m}^{2}$ and $0.5[0.1 ; 0.9] \mathrm{kg} / \mathrm{m}^{2}$ in men and women, respectively. The increasing trend of BMI was more marked in men, while women had steeper BMI and WC trajectories in mid-life.

SBP increased faster between ages 40 and 75 in women than in men: $15.1 \mathrm{mmHg}$ versus $8.9 \mathrm{mmHg}$, which was a $12.9 \%$ and $7.2 \%$ relative increase, respectively. Younger generations had generally lower mean SBP, except elderly men. The unadjusted mean DBP trajectory had its peak around age 50 and then declined markedly. In the adjusted models, younger generations' trajectories started to decline earlier and had lower DBP at any age. 


\section{Men}
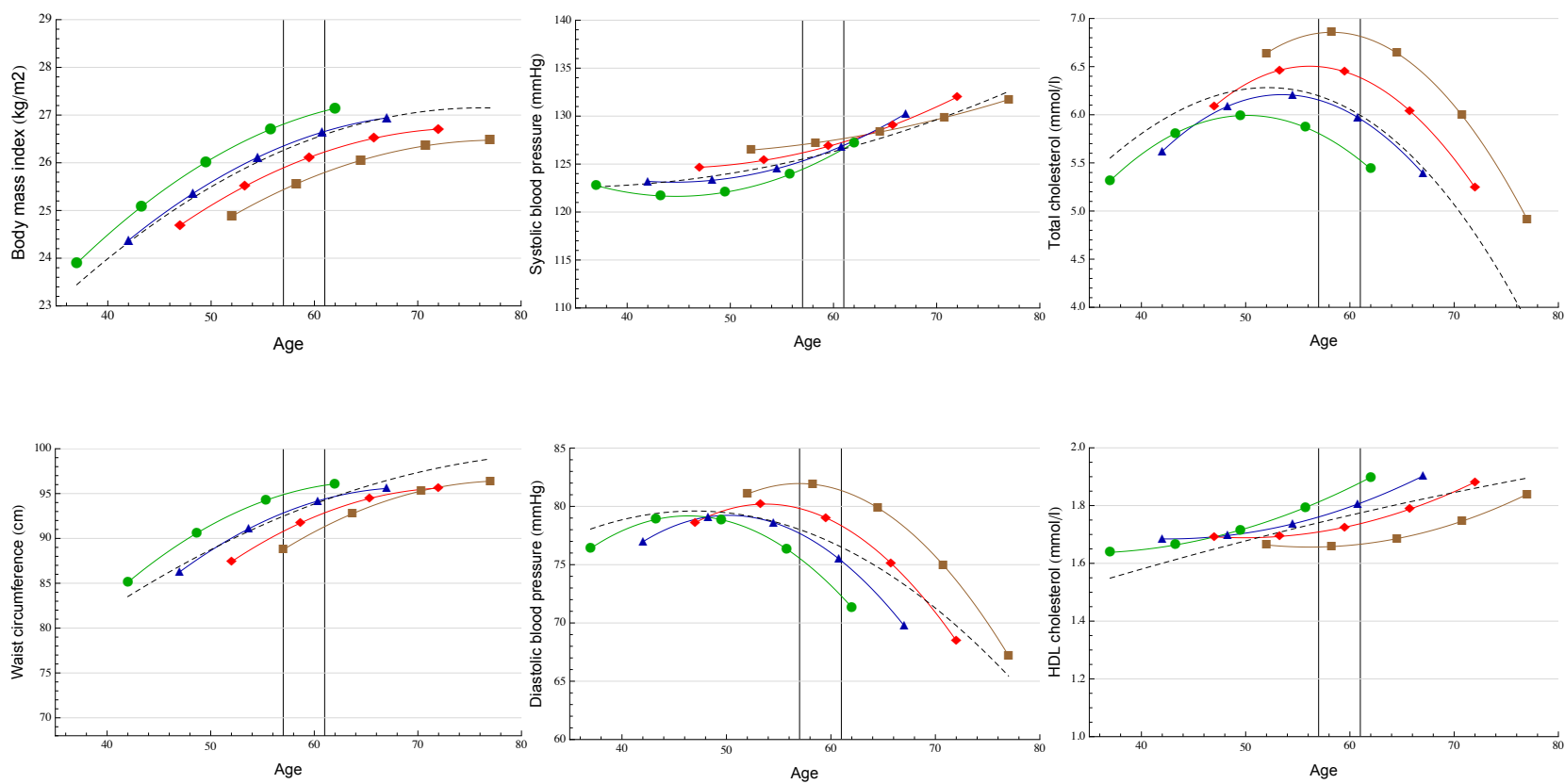

\section{Women}
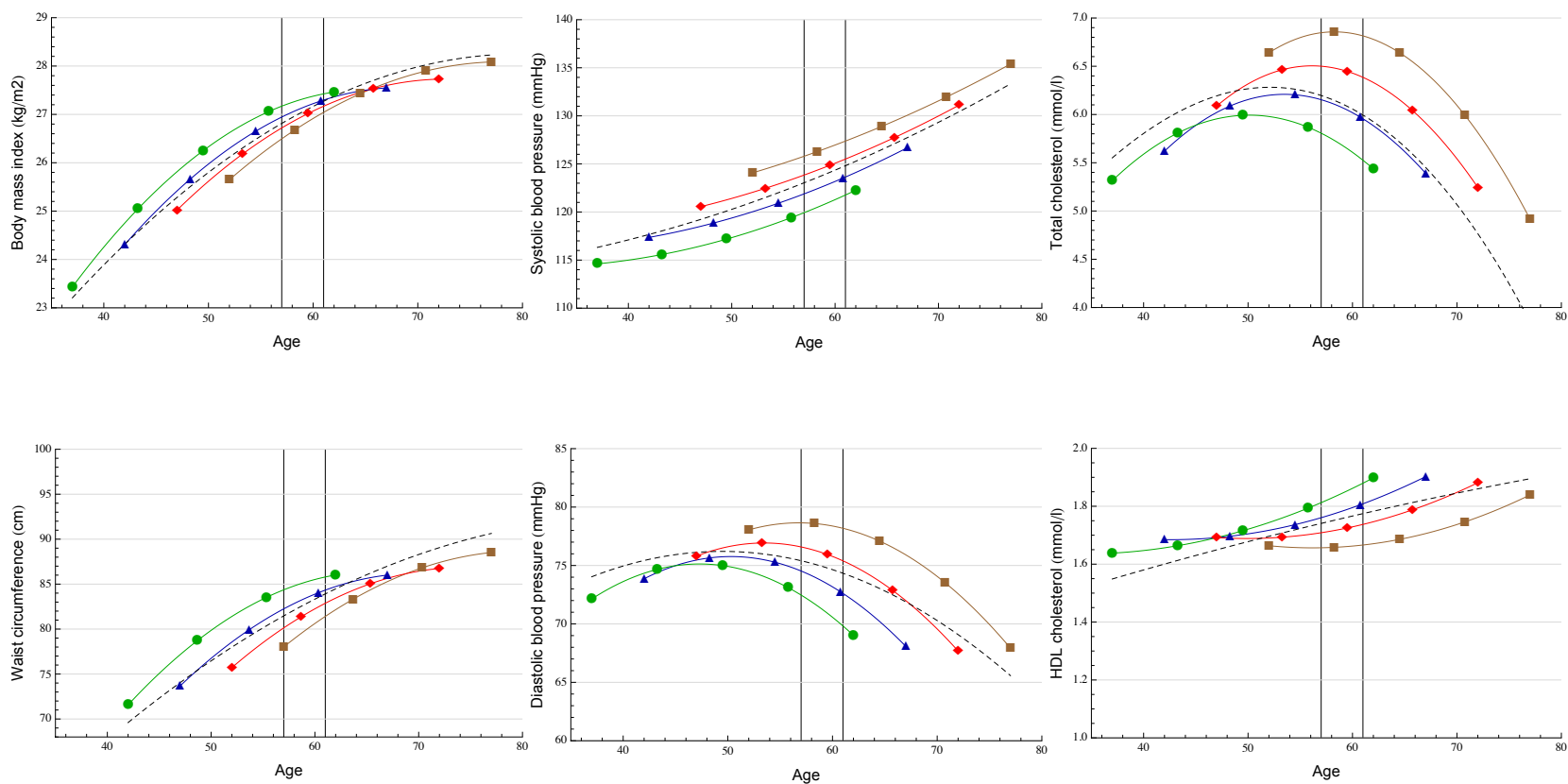

Figure 5 Age-related trajectories of risk factors in men and women with adjustment for four different birth cohorts: $1933(\square), 1938(\diamond), 1943(\Delta), 1948(\bullet)$ and unadjusted (---) 
The unadjusted TC trajectory of men increased up to age 47, peaking at 6.2 [6.2; $6.3] \mathrm{mmol} / \mathrm{l}$. In women, the peak occurred slightly later at age 52 , when the peak value was $6.3[6.3 ; 6.4] \mathrm{mmol} / \mathrm{l}$. At age 60, men born in $1948 \mathrm{had} 1.1[1.0 ; 1.2] \mathrm{mmol} / 1$ lower TC level than men born in 1933, whereas for women the difference between these birth cohorts was $1.2[1.1 ; 1.3] \mathrm{mmol} / \mathrm{l}$. Women had a higher mean HDL cholesterol level than men from mid- to late-adulthood. We observed a modest increase with both age and calendar year.

We found similar associations in our sensitivity analyses when fitting trajectories to a subsample of participants who attended up to phase 9 (data not shown).

\subsection{Diurnal variation of glucose measures}

OGTTs were performed between 08:00 and 15:00 (median 10:42, Q1-Q3: 9:50-11:36), whereas fasting duration ranged from 8 to 20 hours (median 13.4, Q1-Q3: 12.1-14.9). Time of day and fasting duration were moderately correlated (Pearson $r=0.6$, $\mathrm{p}<0.001)$.

The effect of time of day and fasting duration are summarised in Table 10. FPG was inversely associated with both time of day and fasting duration. The mean difference in FPG between measures at 08:00 and 15:00 was -0.46 [-0.50; -0.42$] \mathrm{mmol} / \mathrm{l}$ in men and $-0.39[-0.46 ;-0.31] \mathrm{mmol} / \mathrm{l}$ in women. The effect of fasting duration was markedly attenuated after including both predictors in the model. Time of day and fasting duration were positively associated with $2 \mathrm{hPG}$. The mean difference between measures at 08:00 and 15:00 was $1.39[1.25 ; 1.52] \mathrm{mmol} / \mathrm{l}$ in men and 1.19 [0.96; 1.42] mmol/l in women. Time of day and fasting duration were independently associated with $2 \mathrm{hPG}$ even after the inclusion of both variables in the model. $\mathrm{HbA}_{1 \mathrm{c}}$ levels were neither associated with time of day nor with fasting duration. Models with standardised outcome variables showed that the relative impact of time of day and fasting duration on FPG and $2 \mathrm{hPG}$ were similar of magnitude, but in the opposite direction (Figure 6). 
Table 10 Estimated coefficients of time of day (TD) and fasting duration (FD) from ageand BMI-adjusted mixed-effects models for FPG, $2 \mathrm{hPG}$ and $\mathrm{HbA}_{1 \mathrm{c}}$ with $95 \% \mathrm{CI}$.

\begin{tabular}{cll}
\hline Model variables & Men & Women \\
\hline FPG (mmol/l) & & \\
Only TD (h) & $-0.066[-0.072 ;-0.059]^{* * *}$ & $-0.055[-0.066 ;-0.044]^{* * *}$ \\
Only FD (h) & $-0.033[-0.037 ;-0.028]^{* * *}$ & $-0.024[-0.031 ;-0.017]^{* * *}$ \\
TD and FD & & \\
TD (h) & $-0.059[-0.067 ;-0.050]^{* * *}$ & $-0.053[-0.067 ;-0.039]^{* * *}$ \\
FD (h) & $-0.007[-0.012 ;-0.001]^{*}$ & $-0.002[-0.011 ; 0.007]$ \\
2hPG (mmol/l) & & \\
Only TD (h) & $0.198[0.179 ; 0.217]^{* * *}$ & $0.170[0.137 ; 0.203]^{* * *}$ \\
Only FD (h) & $0.124[0.111 ; 0.137]^{* * *}$ & $0.103[0.083 ; 0.124]^{* * *}$ \\
TD and FD & & \\
TD (h) & $0.128[0.102 ; 0.154]^{* * *}$ & $0.111[0.068 ; 0.154]^{* * *}$ \\
FD (h) & $0.068[0.051 ; 0.085]^{* * *}$ & $0.058[0.030 ; 0.085]^{* * *}$ \\
\hline HbA 1c $(\%)$ & & \\
Only TD (h) & $0.000[-0.007 ; 0.007]$ & $-0.006[-0.018 ; 0.006]$ \\
Only FD (h) & $0.000[-0.004 ; 0.005]$ & $-0.003[-0.011 ; 0.005]$ \\
TD and FD & & \\
TD (h) & $-0.001[-0.009 ; 0.008]$ & $-0.005[-0.021 ; 0.011]$ \\
FD (h) & $0.001[-0.005 ; 0.006]$ & $-0.001[-0.012 ; 0.009]$
\end{tabular}
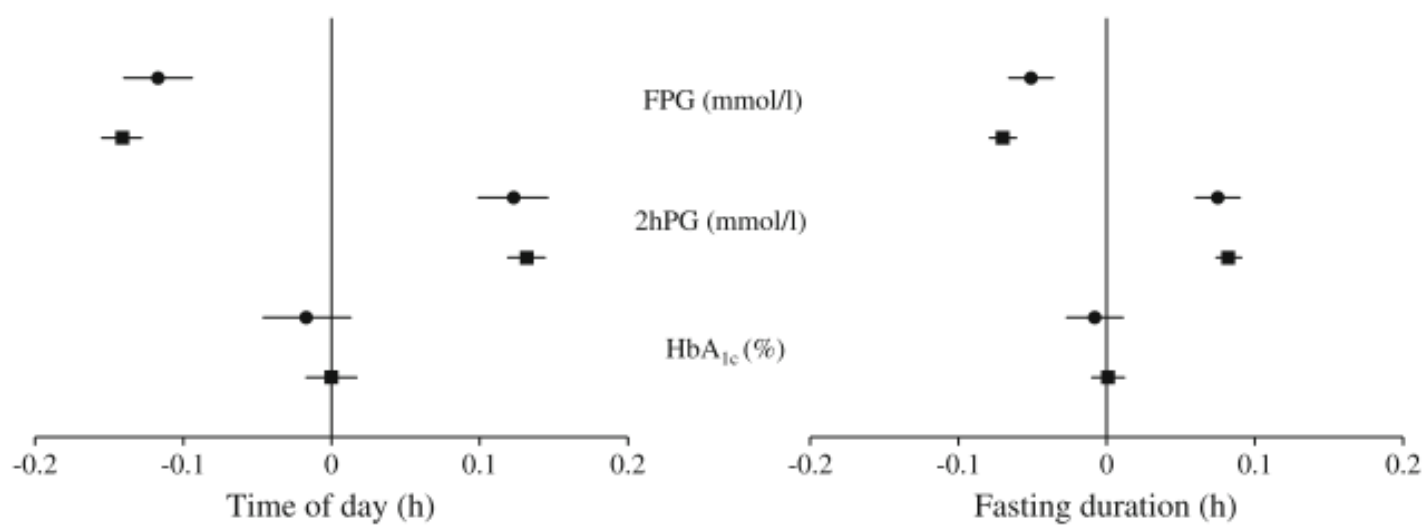

Figure 6 Standardised coefficient estimates of time of day (TD) and fasting duration (FD) for men (squares) and women (circles) with 95\% confidence intervals. Displayed values are the differences caused by an our difference in TD and FD given in standard deviation of each outcome variable 
The modifying effect of age and BMI on the diurnal variation (effect of time of day) of glucose measure is summarised in Table 11. A higher BMI, but not increased age was associated with larger diurnal variation in FPG. We observed the opposite relationship for 2hPG: diurnal variation increased with ageing, but not with BMI.

Table 11 Diurnal variation of fasting plasma glucose by BMI and glucose tolerance ( $2 \mathrm{hPG}$ ) by age (in $\mathrm{mmol} / 1$ per 1 hour).

\begin{tabular}{lccc}
\hline \multirow{2}{*}{ FPG } & 22 & BMI $\left(\mathrm{kg} / \mathrm{m}^{2}\right)$ & 30 \\
\hline men & $-0.05[-0.05 ;-0.04]$ & $-0.07[-0.07 ;-0.06]$ & $-0.09[-0.10 ;-0.08]$ \\
women & $-0.04[-0.05 ;-0.02]$ & $-0.05[-0.07 ;-0.04]$ & $-0.07[-0.09 ;-0.06]$ \\
\hline \multicolumn{2}{c}{ Age (years) } \\
\hline \multirow{2}{*}{ 2hPG } & 45 & 60 & 75 \\
\hline men & $0.15[0.12 ; 0.18]$ & $0.22[0.19 ; 0.24]$ & $0.28[0.23 ; 0.33]$ \\
women & $0.12[0.06 ; 0.17]$ & $0.19[0.16 ; 0.23]$ & $0.27[0.19 ; 0.35]$ \\
\hline
\end{tabular}

We modelled the hypothetical situation that all OGTTs started at 09:00 to investigate the effect of our findings on the diagnosis of diabetes in a clinical setting. The difference between the actual time of the OGTT and 09:00 was calculated (as a real number in hours) and multiplied with the effect size of time of day from the mixed-effects model. This value was added to the actual glucose measures. In this scenario, we found that $15 \%$ of people with WHO-defined diabetes would have not received a diabetes diagnosis. This was mainly driven by lower $2 \mathrm{hPG}$ values when measured hypothetically in the morning. The number of people with "newly" diagnosed diabetes was not clinically relevant. 


\section{DISCUSSION}

\subsection{Maternal obesity and gestational weight gain}

In this study, we investigated the association between BMI, GWG and birthweight with quantile regression, a method that allows us to explore associations along the entire distribution of an outcome. We discuss our results from a public health perspective.

\subsubsection{Geoffrey Rose's population approach}

Geoffrey Rose's population strategy still shapes public health practice and preventive medicine [16-18]. His original idea poses that a smaller shift of the entire distribution of exposure is likely to have a larger impact on risk reduction on a population level, than a targeted approach focusing exclusively on high-risk individuals. This topic still sparks debate in the literature of epidemiology [48-50]. Sophisticated statistical models are necessary to evaluate the effect of hypothetical prevention strategies. Classical regression models focusing on mean values cannot model distributional changes in an outcome variable, because that would assume homogeneity in associations along the entire outcome distribution. Our results showing varying effect sizes of BMI and GWG makes it clear that the assumption of homogeneity does not hold for the BMI-birthweight and the GWG-birthweight association. Use of classical regression may result in an underestimation of the expected decrease in macrosomia and an overestimation of the increase in low birthweight for a given population-wide reduction in GWG. Such results may lead to false conclusions and even decisions on prevention policies. Our analyses suggest that quantile regression is a more suitable tool to describe complex associations than classical regression and calls for further methodological studies to describe and promote statistical models beyond mean regression [51]. Using coefficients estimates from the quantile regression models, we quantified the effect of two hypothetical prevention strategies. The populationbased approach (-2 kg GWG in all individuals) led to decreased dispersion (measured by SD) of the birthweight distribution, which is favourable from a public health perspective. This is the opposite of the common criticism against Rose's population approach and strengthens previous findings suggesting that it does not necessarily increase inequalities $[52,53]$. 


\subsubsection{Targeted interventions}

The population approach is usually set against a population-at-risk strategy that targets only individuals at high risk. Such a strategy can be successful if accurate risk assessment tools are available. Unfortunately, the prediction of fetal macrosomia is a difficult task, even with modern diagnostic tools, because of complex associations of environmental and genetic factors that determine fetal growth [54]. Our hypothetical highrisk strategy targeted overweight and obese women, based on pre-pregnancy BMI, and promoted a more intensive reduction of GWG $(-3 \mathrm{~kg})$ compared with the population approach. Based on our calculation, the high-risk strategy underperformed the population approach in the prevention of macrosomia. This was due to a relatively high proportion of macrosomic infants, who were born to normal weight women. Our study population was relatively lean: $21 \%$ of participants were overweight or obese. The increase in low birthweight following the high-risk strategy was negligible, as expected. This approach of prevention may be more effective in more obese populations.

\subsubsection{Public health implications}

A recent study investigated the effect of GDM, BMI and GWG on the birthweight distribution using quantile regression [55]. The authors reported that individuals at higher risk of having a macrosomic infant (in the right tail of the birthweight distribution) are more vulnerable to changes in BMI and GWG. This finding is concerning if the obesity epidemic continues and may have even more adverse effects on future generations. The authors of the paper also called for further discussion how these results affect prevention stategies targeting individuals at high risk. From the aspect of prevention, we think that the heterogeneous effect of BMI and GWG on birthweight is in fact an opportunity to diminish the right tail of the birthweight distribution without increasing the number of low birthweight infants. Our results showed that a population approach promoting a more modest GWG in all women may offer greater benefits on a population-level, than a highrisk approach in a relatively lean population. This notion highlights the clinical and public health importance of our findings, and the potentially detrimental consequences of using statistical methods that do not model sufficiently the complexity of associations. Our findings cannot be transferred in its original form to all risk factors, but show how quantile regression may help to define risk reduction strategies in the presence of complex associations between risk factors and outcomes. 


\subsubsection{Strengths and limitations}

We analysed the effect of BMI and GWG on birthweight with quantile regression, a method that gives a more complete picture of associations than classical regression models. Although, quantile regression was developed more than 30 years ago, its advantages have not been exploited in the field of epidemiology for a long time. Contrarily to the only recent study investigating the effect of maternal obesity, we had information on treatment received for diabetes during pregnancy, so this important factor, which could have biased previous results, was accounted for in our analysis. Another strength of the study was that BMI and GWG were kept as continuous variables to avoid loss of statistical power.

The hypothetical prevention strategies were arbitrarily chosen and not optimised for the study population. We considered only changes in GWG and not in pre-pregnancy BMI, because in our opinion, although in many countries obese women wanting to be pregnant are adviced to lose weight, women who are already pregnant are more motivated to change their lifestyle habits, than the general population of women in childbearing age. In the high-risk strategy, the targeted group was selected based on BMI using a threshold value of $25 \mathrm{~kg} / \mathrm{m}^{2}$. The efficacy of this strategy could be clearly improved with more complex risk assessment tools, but our aim was mainly to illustrate how quantile regression can help to estimate the effect of prevention strategies more accurately. The relatively healthy and lean study population came from a rather affluent area of Budapest, Hungary, so further investigation is necessary to replicate our results in other populations. Pregnancy outcomes, other than birthweight, should be also analysed in the future.

\subsection{Secular trends and age-related trajectories of risk factors}

We analysed secular trends and the natural progression of BMI, WC, SBP, DBP, TC, HDL with ageing by assessing age-related trajectories based on a large longitudinal dataset from the Whitehall II study (1985-2009). Distributional trends and age-related changes are discussed and compared with other studies.

\subsubsection{Obesity}

Recent results show that the global obesity epidemic is leveling off in younger generations, but increases are still observed among adult populations in Europe and Asia [56]. This highlights the importance of revealing determinants of trends from an 
epidemiological aspect. General obesity trends are usually described by reporting mean BMI levels [4]. These results are easily interpreted, but give no information about the shape of distributions. Another usual approach is to report the prevalence of overweight and obesity [57-59]. This gives more, but still limited information on the higher segment of the BMI distribution. Studies focusing on entire distributions showed an increased rightskewness in the US [19, 20, 60-62], Canada [63], China and in low- and middle-income countries $[62,64]$. These studies were based on sequential cross-sectional analysis of distributions in different population-samples and mainly based on descriptive percentile statistics and to lesser extend on quantile regression [61]. This phenomenon that people who are already obese are more affected by the obesity epidemic was previously called and described as the "runaway weight gain train" [65]. The increasing BMI trend was more marked in men. This finding strengthens previous evidence showing that obesity levels in men are catching up with women [66-68]. One explanation might be a sex difference in the attitude to weight management [69]. Women usually set lower weight goals than men, who also have less attention on their ideal weight.

We observed that while BMI did not increase in leaner groups, they still developed abdominal obesity indicated by a right-shift of the WC distribution's lower segments. A possible explanation is that people lose muscle mass and simultaneously accumulate abdominal fat mass, because of more sedentary lifestyles. Our results are in line with findings in low- and middle-income countries showing a $2-4 \mathrm{~cm}$ increase of $\mathrm{WC}$ at a given level of BMI during a 18 years long period [70]. This notion is even more concerning in light of previous evidence from the InterAct study showing a strong association between abdominal obesity and glucose metabolism independently from general obesity [71]. A recent review highlights the importance of the assessment of $\mathrm{WC}$ in addition to BMI, because it gives independent information on obesity-related mortality [72]. Increasing abdominal obesity is a public health concern that affect both sexes similarly and calls for more attention on the development of prevention strategies.

Our longitudinal trajectory analyses showed that younger generations experience a greater cumulative exposure to obesity. Participants born only 15 years later (in 1948 versus 1933), reached overweight 10 and 6 years earlier in their life-course in men and women, respectively. We observed similar patterns in WC trajectories. The clinical importance of these results are emphasised by recent findings of the CARDIA study [73]. 
The authors showed that a longer duration of general and abdominal obesity was linked to coronary heart disease in midlife. The association was independent of the degree of adiposity. This notion suggests that younger birth cohorts might be at a greater cardiometabolic risk and that prevention of obesity is of major importance already at an early age in the life-course. On the other hand, another study reported that reaching a healthy weight is not too late in adulthood [74]. Their prospective analyses showed that participants who were overweight or obese during childhood but not anymore in adulthood had similar risk of type 2 diabetes, dyslipidemia and atherosclerosis, compared with those who were never overweight or obese.

Our analyses clearly showed that cohort effect should not be ignored when assessing age-related trajectories. While the oldest participants of the Whitehall II cohort grew up in the austerity of the 1930s, younger generations were born in the period of postwar reconstruction, increasing welfare and food security. Recent results show that such effects still exists, as the height and weight of 6-year-old children increased in the last 30 years and obesity prevalence continues to rise in less affluent populations [75]. Age-related changes cannot be analysed adequately based on cross-sectional data. A previous study reported that age-related increases in BMI might be underestimated in such analyses [76]. In addition, we argue that longitudinal analyses give biased estimates when cohort effects are ignored. Therefore we modelled cohort effects by adding year of birth (time-invariant variable) and its interaction with age to the models. The interaction term is responsible for the different curve characteristics (e.g. curvature and slope at a given age). Keeping age and year of birth as continuous variables is advisable to retain statistical power.

\subsubsection{Blood pressure}

Contrary to our observations in obesity measures, distributional trends in SBP were not consistent in one direction between phases. A marked decline was observed only between phase 7 and 9, especially in women. We cannot fully attribute this decline to a wider use of antihypertensive medication, because that increased already between earlier phases. In contrast, both our sequential cross-sectional and longitudinal analyses confirm a marked decline in DBP. The drop was similar along the entire distribution, which resulted a left-shift of the distribution. Regarding the age-related blood pressure trajectories, our results are in line with current understanding that SBP rises from mid to late adulthood (more rapidly among women), while DBP peaks around the age of 50 years and then starts 
to decline, because of increasing aortic and small vessel stiffness [45, 77]. Compared to previous studies, our analyses accounted for secular trends and cohort effects that made it possible to observe different trajectory characteristics between birth cohorts. In addition to generally lower DBP levels, we also found that the decline started at a lower age in younger birth cohorts. As DBP is inversely associated with the risk of coronary heart disease after age 60 , this notion imposes additional risk on younger birth cohorts [78]. The decreasing trends in SBP and especially in DBP have to be interpreted with caution. As DBP decreases with age while SBP increases, a widening gap develops between SBP and DBP that leads to an increasing pulse pressure, which is an independent determinant of the coronary heart disease [79]. In addition to an increase with ageing, pulse pressure has also increased with calendar year, leading to an additional risk of CVD due to a combined cohort and period effect.

\subsubsection{Cholesterol}

In contrast to previous studies, which reported trends based on mean levels, we analysed secular trends along the entire TC distribution. Our results showed a marked leftshift of the entire distribution, which extends previous knowledge on decreasing trends [6, $80,81]$. Although the observed decline may be partially due to the wider use of statins, especially in elderly, this cannot be the only cause, as values decreased in the left tail of the distribution too. This finding is in line with previous reports from developed countries emphasising the importance of positive changes in dietary patterns [46, 82]. They also argue that the marked decline started already before statins were introduced and further regulatory interventions are necessary to promote the use of healthier fats. Our analyses showed that the age-related trajectories of younger cohorts started to decline at younger ages in the life-course. It is likely because of decreasing thresholds above which lipidlowering treatment is prescribed. The effect of secular trends and cohort effects were so large during the last three decades that an unadjusted TC trajectory clearly underestimates true trajectories in late adulthood. This effect makes it a challenging task to isolate the effect of ageing from trends. Trends in HDL cholesterol are rarely investigated. Both of our models suggest favourable changes in HDL cholesterol levels in the last three decades. Although changes in HDL cholesterol were modest compared to TC. 


\subsubsection{Strengths and limitations}

When analysing secular trends, we did not only report mean levels of risk factors, but considered entire distribution characteristics. Quantile regression is a suitable tool for such analyses. Age-related trajectories were assessed based on a long period of observation (25 years) with up to five repeated measurements per person. Secular trends, cohort effects and ageing were considered simultaneously in our analyses.

Handling missing data and attrition are important tasks when analysing longitudinal data. When the pattern of missingness is MAR, mixed-effects models give valid estimates for the age-related trajectories. To handle the case of MNAR, we conducted sensitivity analyses on a subgroup of individuals who participated up to phase 9. These analyses replicated our main findings, indicating that it is unlikely that loss to follow-up biased our age-trajectory estimates. When the follow-up period is long, standardisation of measurements is crucial and cannot be ignored. All laboratories participated in the National External Quality Assurance Scheme for TC and HDL cholesterol. Regarding blood pressure measures, it is unlikely that decreasing trends were due to changes in measurement device, because AOD used in the last two phases, produces slightly higher values than MRZ [83]. Our results were based on an occupational cohort study. Such cohorts are usually healthier than the general population. Previous studies from the Whitehall II study showed lower mortality rates [84], lower SBP trajectories, but similar BMI trajectories compared with population-based cohorts [45]. Another limitation of our sequential cross-sectional analysis, was that we could analyse only the 57-61 age group. Further research is necessary to confirm our results on a population level.

\subsection{Diurnal variation of glucose measures}

\subsubsection{Diabetes diagnosis}

Diurnal variation of glucose tolerance has not received much attention in the past decades, even though the definition of diabetes has been based on fasting and/or 2-hour post-OGTT values since 1965. After the recent introduction of $\mathrm{HbA}_{1 \mathrm{c}}$ as an additional diagnostic criterion, analyses investigating the overlap between $\mathrm{HbA}_{1 \mathrm{c}}$ and OGTT based diabetes diagnosis have implicitly assumed the OGTT to be a type of gold standard. Previous studies also showed a significant intra-individual variation of glucose measures. This result had important clinical implications: approximately $20 \%$ of patients who 
received a diagnosis based on an OGTT, would not have a diagnosis when retested [85]. Our analysis, based on a large sample of repeated measures in a well characterised cohort, shows that even a few hours difference in fasting duration or sampling time can affect whether or not somebody is diagnosed as having diabetes based on an OGTT.

\subsubsection{Fasting glucose}

The observed decline in FPG levels during the day is in line with previous findings, which also showed clinically relevant differences between morning and early afternoon FPG measures [28]. Our findings support the notion that standardisation of fasting duration and time of day is an important point in the protocols of epidemiological studies [29]. Glucose measures even from fasting subjects are not necessarily unbiased, so adjustment for timing factors is advisable if data are available. These results indicate that timing should not be ignored when diagnosing diabetes, or comparing individual glucose levels longitudinally in clinical practice. Our results are also consistent with previous findings on the modest role of fasting duration in addition to time of day [30]. We agree with the authors conclusions that more effort on the standardisation or assessment of other factors, like diet and physical activity, is necessary.

\subsubsection{Glucose tolerance ( $2 \mathrm{hPG})$}

Our results are consistent with previous evidence, indicating higher $2 \mathrm{hPG}$ levels in the afternoon than in the morning [25-27]. We also confirmed the notion that diurnal variation in glucose tolerance increases with age. However, we found no clear evidence to suggest that obesity would reduce diurnal variation in $2 \mathrm{hPG}$ [26]. A previous review reported that there is no evidence for an effect of fasting duration in addition to time of day [86]. In contrast, fasting duration improved our models for $2 \mathrm{hPG}$ even if time of day was accounted for. This difference might be because of the lack of statistical power or different protocols regarding fasting duration in previous studies. Although the studies are not directly comparable, our results support the recent finding of an underestimation of glucose tolerance among pregnant women who had an afternoon rather than a morning 1-hour, $50 \mathrm{~g}$, non-fasting glucose challenge test, as compared to a confirmatory morning 3-hour, $100 \mathrm{~g}$ fasting OGTT performed on a separate day [87].

\subsection{4 $\mathrm{HbA}_{1 \mathrm{c}}$}

$\mathrm{HbA}_{1 \mathrm{c}}$ reflects blood glucose concentrations retrospectively in the previous 2-3 months. As a result of a WHO expert consultation in 2009 , it was recently accepted as a 
new diagnostic tool for diabetes. A recent study reported that $\mathrm{HbA}_{1 \mathrm{c}}$ is not only useful to predict future diagnosis of diabetes, but had an even stronger association with the risk of CVD and death from all cause mortality than FPG [88]. Similarly stronger associations were found between $\mathrm{HbA}_{1 \mathrm{c}}$ and ischaemic heart disease in a large Danish population [89]. In addition to these findings, one of the most important features of an $\mathrm{HbA}_{1 \mathrm{c}}$ test remains the independence of results from time of day and fasting duration. We confirmed this notion in a large occupational cohort study.

\subsubsection{Strengths and limitations}

The key strength of our study was that we did not categorise time of day and fasting duration. This was possible because of the detailed assessment of variables. Another strength of our study was, that we analysed all three measures parallel in the same population. However, the relatively low proportion of women in the study resulted in wider confidence intervals for their coefficient estimates. The longitudinal structure of the dataset was neither an advantage nor a disadvantage, because it was handled according to common practice by adding random effects to the models and adjusting them for study phase. Our analyses were based on data from an occupational cohort, that is known to be relatively healthier than the general population. Further research is needed to examine the generalisability of our findings to other populations, ethnic groups and pregnant women. 


\section{SUMMARY AND CONCLUSIONS}

Maternal obesity and GWG are targets for prevention of adverse pregnancy outcomes related to birthweight. Using quantile regression, we found that GWG was positively associated with infant birthweight, however in leaner women its effect was heterogeneous along the distribution of birthweight and increased towards higher percentiles. Classical regression models cannot reveal such differences and give a rather incomplete picture of associations. We also evaluated the effect of hypothetical prevention strategies on the birthweight distribution. We concluded that a population-wide lowering of GWG would not lead to a uniform left-shift of the birthweight distribution, but that the right tail would be more affected and the total variance would decrease. Our findings support the promotion of strategies to lower GWG on a population-level. These results indirectly imply that current GWG guidelines might be too permissive. We also conclude that quantile regression is a useful tool for epidemiologists and public health practitioners to investigate complex, distributional associations of risk factors and outcomes.

The past 25 years brought marked changes in cardiometabolic risk factors. Younger generations were more obese, than their older peers at any given age. Contrarily, we observed a more favourable lipid profile (i.e. lower TC levels and higher HDL cholesterol levels) in younger cohorts. Furthermore, the observed secular trends affected the shape of risk factor distributions. Whereas the increase in obesity led to more right-skewness, the decreases in TC and interestingly in DBP were characterised by a left-shift of the entire distributions. These results show that the last three decades brought strong and heterogeneous secular trends in obesity, blood pressure and lipid levels. Decreasing CVD mortality in the UK suggest that the negative trends in obesity are counterbalanced by favourable changes in other risk factors. The disparity of these trends indicate that the relative importance of these risk factors is likely to change over time. This observation has potential implications for the way we assess global CVD risk based on risk scores, highlighting the need to reassess the calibration of component weights on a regular basis. Our findings also suggest that more detailed models of risk factor progression may be needed to help track the development not only of mean levels but also changing risk factor distributions in the population. Secular trends caused by period and cohort effects should be considered in longitudinal analyses of age-related risk factor trajectories to avoid biased estimates. 
The diagnosis of diabetes is based on blood glucose levels, therefore the investigation of factors influencing glucose levels on a population level is an important task from an epidemiological perspective. Based on a large sample, we showed that time of blood sampling and duration of fasting prior to blood sampling affect FPG and 2hPG levels considerably. As expected, neither of these factors affected $\mathrm{HbA}_{1 \mathrm{c}}$. Furthermore we showed how age and BMI affect the diurnal variation of glucose tolerance and fasting glucose measures. These results highlight the importance of standardising the diagnostic OGTT regarding time of day and fasting duration that is often overlooked in clinical practice and in epidemiological investigations. FPG and 2hPG measures vary by different fasting duration periods even after 8 hours of fasting, independently of time of blood sampling. This finding suggests that the current WHO recommendation may not be strict enough regarding time of blood sampling and fasting duration and adjustment for these factors is necessary in clinical practice and epidemiological studies.

Epidemiology provides the scientific basis for public health practice by exploring the "occurrence and distribution of health-related states or events in specified populations, including the study of the determinants influencing such states, and the application of this knowledge to control the health problems" [90]. Our studies demonstrated that the use of appropriate statistical methods is crucial when exploring the relative importance of risk factors and their associations with health-related outcomes, identifying subgroups at risk and evaluating the effectiveness of prevention strategies. With the knowledge gathered in developed countries, where CVD incidence already seems to be declining, a huge burden of disease can hopefully be prevented in developing countries which are going through similar economical and societal changes to those that were already seen in high-income regions. Adequate control of modifiable risk factors is a key tool to achieve this goal. 


\section{Novelties and key messages}

Maternal obesity and gestational weight gain

- We demonstrated the rarely exploited potential of quantile regression in public health and preventive medicine.

- The association between gestational weight gain and birthweight was altered by BMI and was heterogeneous in leaner women.

- Based on a statistical model, we found that a population-based intervention promoting a more modest gestational weight gain might offer more favourable changes in the birthweight distribution, than a high-risk approach.

Secular trends and age-related trajectories of risk factors

- Trends of cardiometabolic risk factors were described using sophisticated statistical methods focusing on entire distribution characteristics and not only on mean levels.

- The obesity epidemic affected those already overweight and obese, which led to increasing dispersion and right-skewness of distributions.

- The marked drop in diastolic blood pressure has to be interpreted with caution, because of its negative effects in elderly and the increasing pulse pressure.

- Secular trends were strong and heterogeneous in the last decades and therefore should be taken into account when analysing age-related trajectories to avoid biased estimates caused by large differences between successive birth cohorts.

Diurnal variation of glucose measures

- We investigated the combined effect of time of day and fasting duration on all three glucose measures, based on a large sample.

- We gave estimates for the magnitude of diurnal variation by keeping time of day and fasting duration as continuous variables.

- Time of blood sampling and fasting duration have clinically relevant effects on glucose measures even if WHO recommendations are followed. 


\section{ACKNOWLEDGEMENTS}

During the last few years I have received support and encouragement from a great number of individuals.

First of all, I would like to thank Daniel R. Witte, my external supervisor for his invaluable support and guidance during my Ph.D. studies. I feel very lucky that he introduced me to the field of epidemiology and that we are working together. I have learnt a lot during our conversations and from his insightful comments on our papers, presentations and the present thesis. Special thanks go to him also for introducing me to the European Diabetes Epidemiology Group, we had some memorable meetings in the last three years.

I would like to express my gratitude to my supervisors in Szeged: János Karsai and Tibor Nyári for their motivation, support and patience. János played an important role in that I ended up pursuing a career in life sciences as an applied mathematician. He gave me the first real-life problems to inspire me when I was still studying mathematics and invited me to the Department of Medical Physics and Informatics, my current workplace. Tibor helped me a lot to get more experience in biostatistics and epidemiology, and was always extremely encouraging with me.

I would like to express my gratitude to Ferenc Bari, head of the Department of Medical Physics and Informatics for his support and advice on my career.

I would like to give special thanks to Grant Fuller and Balázs Boros, my former colleagues in London, for their motivation and support. It was a fantastic opportunity for me to work with them, which really formed my professional attitude.

I would also like to thank some of my co-authors: Ádám Tabák (Semmelweis University), Dorte Vistisen, Kristine Færch (Steno Diabetes Center), Eric J. Brunner and Mika Kivimäki (UCL) for their help and useful comments on our papers.

I am also grateful to my colleagues at my home institute, especially to my fellow $\mathrm{Ph} . \mathrm{D}$. students. It was a pleasure to have some fun with them during lunchtimes.

Last but not least, I also wish to thank my family, especially my parents and my wife for their constant support, encouragement and patience. 


\section{REFERENCES}

1. World Health Organization. Global status report on noncommunicable diseases 2010. Available at: http://www.who.int/nmh/publications/ncd_report2010/en/ (Accessed: 3 April 2014)

2. Zhang P, Zhang X, Brown J, et al. Global healthcare expenditure on diabetes for 2010 and 2030. Diabetes Res Clin Pract 2010;87:293-301.

3. Mahmood SS, Levy D, Vasan RS, Wang TJ. The Framingham Heart Study and the epidemiology of cardiovascular disease: a historical perspective. Lancet 2014;383:999-1008.

4. Finucane MM, Stevens GA, Cowan MJ, et al. National, regional, and global trends in body-mass index since 1980: systematic analysis of health examination surveys and epidemiological studies with 960 country-years and $9 \cdot 1$ million participants. Lancet 2011;377:557-67.

5. Danaei G, Finucane MM, Lin JK, et al. National, regional, and global trends in systolic blood pressure since 1980: systematic analysis of health examination surveys and epidemiological studies with 786 country-years and 5.4 million participants. Lancet 2011;377:568-77.

6. Farzadfar F, Finucane MM, Danaei G, et al. National, regional, and global trends in serum total cholesterol since 1980: systematic analysis of health examination surveys and epidemiological studies with 321 country-years and $3 \cdot 0$ million participants. Lancet 2011;377:578-86.

7. Danaei G, Finucane MM, Lu Y, et al. National, regional, and global trends in fasting plasma glucose and diabetes prevalence since 1980: systematic analysis of health examination surveys and epidemiological studies with 370 country-years and $2 \cdot 7$ million participants. Lancet 2011;378:31-40.

8. Anand SS, Yusuf S. Stemming the global tsunami of cardiovascular disease. Lancet 2011;377:529-32.

9. Heslehurst N, Rankin J, Wilkinson JR, et al. A nationally representative study of maternal obesity in England, UK : trends in incidence and demographic inequalities in 619323 births, 1989-2007. Int J Obes 2010;34:420-8.

10. Han Z, Mulla S, Beyene J, et al. Maternal underweight and the risk of preterm birth and low birth weight: a systematic review and meta-analyses. Int J Epidemiol 2011;40:65-101.

11. Mcdonald SD, Han Z, Mulla S, et al. Overweight and obesity in mothers and risk of preterm birth and low birth weight infants: systematic review and meta-analyses. BMJ 2010;341:c3428.

12. Oza-Frank R, Keim SA. Should Obese Women Gain Less Weight in Pregnancy Than Recommended? Birth 2013;40:107-114.

13. IOM (Institute of Medicine) and NRC (National Research Council). Weight gain during pregnancy: reexamining the guidelines. Washington D.C.: The National Academies Press; 2009. 
14. Nohr EA, Vaeth M, Baker JL, et al. Combined associations of prepregnancy body mass index and gestational weight gain with the outcome of pregnancy. Am J Clin Nutr 2008;87:1750-9.

15. Keyes KM, Utz RL, Robinson W, et al. What is a cohort effect? Comparison of three statistical methods for modeling cohort effects in obesity prevalence in the United States, 1971-2006. Soc Sci Med 2010;70:1100-8.

16. Rose G. Strategy of prevention: lessons from cardiovascular disease. $B M J$ 1981;282:1847-51.

17. Rose G. Sick individuals and sick populations. Int J Epidemiol 1985;14:32-8.

18. Doyle YG, Furey A, Flowers J. Sick individuals and sick populations: 20 years later. J Epidemiol Community Health. 2006;60:396-8.

19. Flegal KM, Troiano RP. Changes in the distribution of body mass index of adults and children in the US population. Int J Obes 2000;24:807-18.

20. Penman AD, Johnson WD. The changing shape of the body mass index distribution curve in the population: implications for public health policy to reduce the prevalence of adult obesity. Prev Chronic Dis 2006; 3:A74.

21. Long GH, Simmons RK, Norberg M, et al. Temporal shifts in cardiovascular risk factor distribution. Am J Prev Med 2014;46:112-21.

22. World Health Organization and International Diabetes Federation. Definition and diagnosis of diabetes mellitus and intermediate hyperglycemia (2006). Available at: http://www.who.int/diabetes/publications/diagnosis_diabetes2006/en/

(Accessed: 3 April 2014)

23. World Health Organization. Use of glycated haemoglobin (HbA1c) in the diagnosis of diabetes mellitus (2011). Available at:

http://www.who.int/diabetes/publications/diagnosis diabetes2011/en/

(Accessed: 3 April 2014)

24. Goldstein DE, Little RR, Lorenz RA, et al. Tests of glycemia in diabetes. Diabetes Care 2004;27:1761-73.

25. Jarrett RJ, Keen H. Diurnal variation of oral glucose tolerance: a possible pointer to the evolution of diabetes mellitus. BMJ 1969;2:341-4.

26. Zimmet PZ, Wall JR, Rome R, et al. Diurnal variation in glucose tolerance: associated changes in plasma insulin, growth hormone, and non-esterified fatty acids. $B M J 1974 ; \mathbf{1}: 485-8$.

27. Mayer KH, Stamler J, Dyer A, et al. Epidemiologic findings on the relationship of time of day and time since last meal to glucose tolerance. Diabetes 1976;25:93643.

28. Troisi RJ, Cowie CC, Harris MI Diurnal variation in fasting plasma glucose: implications for diagnosis of diabetes in patients examined in the afternoon. JAMA 2000;284:3157-9.

29. Emberson JR, Whincup PH, Walker M, et al. Biochemical measures in a population-based study : effect of fasting duration and time of day. Ann Clin Biochem 2002;39:493-501. 
30. Moebus S, Göres L, Lösch C, et al. Impact of time since last caloric intake on blood glucose levels. Eur J Epidemiol 2011;26:719-28.

31. World Health Organization. Definition, diagnosis and classification of diabetes mellitus and its complications (1999). Available at:

http://whqlibdoc.who.int/hq/1999/who_ncd ncs 99.2.pdf

(Accessed: 3 April 2014)

32. Mosteller F, Tukey JW. Data analysis and regression: a second course in statistics. Reading, MA: Addison-Wesley; 1977.

33. Abrevaya $\mathrm{J}$. The effects of demographics and maternal behavior on the distribution of birth outcomes. Empir Econ. 2001;26:247-57.

34. Koenker R, Bassett G, Jan N. Regression Quantiles. Econometrica 1978;46:33-50.

35. Koenker R, Hallock KF. Quantile Regression. J Econ Perspect 2001;15:143-56.

36. Koenker R. quantreg: Quantile regression. R package version 4.97.

Available at: http://www.inside-r.org/packages/cran/quantreg

(Accessed: 3 April 2014)

37. Singer J, Willett J. Applied longitudinal data analysis: modeling change and event occurence. New York, NY: Oxford University Press; 2003.

38. Gałecki A, Burzykowski T. Linear mixed-effects models using R. New York, NY: Springer; 2013.

39. Bates DM. lme4: Mixed-effects modeling with R. Available at: http://lme4.r-forge.r-project.org/lMMwR/lrgprt.pdf (Accessed: 3 April 2014)

40. Kerényi Z, Tamás G, Kivimaki M, et al. Maternal glycemia and risk of large-forgestational-age babies in a population-based screening. Diabetes Care 2009;32:2200-5.

41. Marmot M, Brunner E. Cohort Profile: the Whitehall II study. Int J Epidemiol 2005;34:251-6.

42. Tabák AG, Jokela M, Akbaraly TN, et al. Trajectories of glycaemia, insulin sensitivity, and insulin secretion before diagnosis of type 2 diabetes: an analysis from the Whitehall II study. Lancet 2009;373:2215-21.

43. Stringhini A, Tabák AG, Akbaraly TN, et al. Contribution of modifiable risk factors to social inequalities in type 2 diabetes: prospective Whitehall II cohort study. BMJ 2012;345:e5452.

44. Færch K, Witte DR, Tabák AG, et al. Trajectories of cardiometabolic risk factors before diagnosis of three subtypes of type 2 diabetes: a post-hoc analysis of the longitudinal Whitehall II cohort study. Lancet Diabetes Endocrinol 2013;1:43-51.

45. Wills AK, Lawlor DA, Matthews FE, et al. Life course trajectories of systolic blood pressure using longitudinal data from eight UK cohorts. PLoS Med 2011;8:e1000440. 
46. Bouillon K, Singh-Manoux A, Jokela M, et al. Decline in low-density lipoprotein cholesterol concentration: lipid-lowering drugs, diet, or physical activity? Evidence from the Whitehall II study. Heart 2011;97:923-30.

47. Faerch K, Borch-Johnsen K, Vaag a, et al. Sex differences in glucose levels: a consequence of physiology or methodological convenience? The Inter99 study. Diabetologia 2010;53:858-65.

48. Frohlich KL, Potvin L. Transcending the known in public health practice: the inequality paradox: the population approach and vulnerable populations. $\mathrm{Am} J$ Public Health 2008;98:216-21.

49. Zulman DM, Vijan S, Omenn GS, et al. The relative merits of population-based and targeted prevention strategies. Milbank $Q$ 2008;86:557-80.

50. Ahern J, Jones MR, Bakshis E, et al. Revisiting rose: comparing the benefits and costs of population-wide and targeted interventions. Milbank $Q$ 2008;86:581-600.

51. Kneib T. Beyond mean regression. Stat Model 2013;13:275-303.

52. Liu SY, Kawachi I, Glymour MM. Education and inequalities in risk scores for coronary heart disease and body mass index: evidence for a population strategy. Epidemiology 2012;23:657-64.

53. McLaren L, McIntyre L, Kirkpatrick S. Rose's population strategy of prevention need not increase social inequalities in health. Int J Epidemiol 2010;39:372-7.

54. Walsh JM, McAuliffe FM. Prediction and prevention of the macrosomic fetus. Eur J Obstet Gynecol Reprod Biol 2012;162:125-30.

55. Ellerbe CN, Gebregziabher M, Korte JE, et al. Quantifying the impact of gestational diabetes mellitus, maternal weight and race on birthweight via quantile regression. PLoS One 2013;8:e65017.

56. Rokholm B, Baker JL, Sørensen TIA. The levelling off of the obesity epidemic since the year 1999 - a review of evidence and perspectives. Obes Rev 2010;11:835-46.

57. Flegal KM, Carroll MD, Ogden CL, et al. Prevalence and trends in obesity among US adults, 1999-2000. JAMA 2002;288:1723-7.

58. Flegal KM, Carroll MD, Ogden CL, et al. Prevalence and trends in obesity among US adults, 1999-2008. JAMA 2010;303:235-41.

59. Flegal KM, Carroll MD, Kit BK, Ogden CL. Prevalence of obesity and trends in the distribution of body mass index among US adults, 1999-2010. JAMA 2012;307:491-7.

60. Gordon-Larsen P, Adair LS, Nelson MC, et al. Five-year obesity incidence in the transition period between adolescence and adulthood: the National Longitudinal Study of Adolescent Health. Am J Clin Nutr 2004;80:569-75.

61. Bottai M, Frongillo EA, Sui X, et al. Use of quantile regression to investigate the longitudinal association between physical activity and body mass index. Obesity 2013;doi:10.1002/oby.20618. 
62. Razak F, Corsi DJ, Subramanian SV. Change in the body mass index distribution for women: analysis of surveys from 37 low- and middle-income countries. PLoS Med 2013;10:e1001367.

63. Katzmarzyk PT. The Canadian obesity epidemic: an historical perspective. Obes Res 2002;10:666-74.

64. Xi B, Liang Y, He T, et al. Secular trends in the prevalence of general and abdominal obesity among Chinese adults, 1993-2009. Obes Rev 2012;13:287-96.

65. Swinburn B, Egger G. The runaway weight gain train: too many accelerators, not enough brakes. BMJ 2004;329:736-9.

66. Cabrera C, Wilhelmson K, Allebeck P, Wedel H, Steen B, Lissner L. Cohort differences in obesity-related health indicators among 70-year olds with special reference to gender and education. Eur J Epidemiol 2003;18:883-90.

67. Eiben G, Dey DK, Rothenberg E, et al. Obesity in 70-year-old Swedes: secular changes over 30 years. Int J Obes 2005;29:810-7.

68. Lahti-Koski M, Jousilahti P, Pietinen P. Secular trends in body mass index by birth cohort in eastern Finland from 1972 to 1997. Int J Obes 2001;25:727-34.

69. Crawford D, Campbell K. Lay definitions of ideal weight and overweight. Int $J$ Obes Relat Metab Disord 1999;23:738-45.

70. Popkin BM, Slining MM. New dynamics in global obesity facing low- and middleincome countries. Obes Rev 2013; doi:10.1111/obr.12102.

71. The InterAct Consortium. Long-term risk of incident type 2 diabetes and measures of overall and regional obesity: the EPIC-InterAct case-cohort study. PLoS Med 2012;9:e1001230.

72. Carmienke S, Freitag MH, Pischon T, et al. General and abdominal obesity parameters and their combination in relation to mortality: a systematic review and meta-regression analysis. Eur J Clin Nutr 2013;67:573-85.

73. Reis JP, Loria CM, Lewis CE, et al. Association Between Duration of Overall and Abdominal Obesity Beginning in Young Adulthood and Coronary Artery Calcification in Middle Age. JAMA 2013;310:280-8.

74. Juonala M, Magnussen CG, Berenson GS, et al. Childhood adiposity, adult adiposity, and cardiovascular risk factors. N Engl J Med 2011;365:1876-85.

75. Smith SM, Craig LCA, Raja AE, McNeill G, Turner SW. Growing up before growing out: secular trends in height, weight and obesity in 5--6-year-old children born between 1970 and 2006. Arch Dis Child 2013;98:269-73.

76. Nooyens ACJ, Visscher TLS, Verschuren WMM, et al. Age, period and cohort effects on body weight and body mass index in adults: The Doetinchem Cohort Study. Public Health Nutr 2009;12:862-70.

77. Cheng S, Xanthakis V, Sullivan LM, Vasan RS. Blood pressure tracking over the adult life course: patterns and correlates in the Framingham heart study.

Hypertension 2012;60:1393-9. 
78. Franklin SS, Larson MG, Khan SA, et al. Does the relation of blood pressure to coronary heart disease risk change with aging? : The Framingham Heart Study. Circulation 2001;103:1245-9.

79. Assmann G, Cullen P, Evers T, Petzinna D, Schulte H. Importance of arterial pulse pressure as a predictor of coronary heart disease risk in PROCAM. Eur Heart J 2005;26:2120-6.

80. Arnett DK, Jacobs DR, Luepker RV, Blackburn H, Armstrong C, Claas SA. Twenty-year trends in serum cholesterol, hypercholesterolemia, and cholesterol medication use: the Minnesota Heart Survey, 1980-1982 to 2000-2002. Circulation 2005;112:3884-91.

81. Scholes S, Bajekal M, Love H, et al. Persistent socioeconomic inequalities in cardiovascular risk factors in England over 1994-2008: a time-trend analysis of repeated cross-sectional data. BMC Public Health 2012;12:129.

82. Capewell S, Ford ES. Why have total cholesterol levels declined in most developed countries? BMC Public Health 2011;11:641.

83. Stang A, Moebus S, Möhlenkamp S, et al. Algorithms for converting random-zero to automated oscillometric blood pressure values, and vice versa. Am J Epidemiol 2006;164:85-94.

84. Singh-Manoux A, Guéguen A, Ferrie J, et al. Gender differences in the association between morbidity and mortality among middle-aged men and women. Am J Public Health 2008;98:2251-7.

85. Selvin E, Crainiceanu CM, Brancati FL, et al. Short-term variability in measures of glycemia and implications for the classification of diabetes. Arch Intern Med 2007;167:1545-51.

86. Van Cauter E, Polonsky KS, Scheen AJ. Roles of circadian rhythmicity and sleep in human glucose regulation. Endocr Rev 1997;18:716-38.

87. Goldberg RJ, Ye C, Sermer M, et al. Circadian variation in the response to the glucose challenge test in pregnancy: implications for screening for gestational diabetes mellitus. Diabetes Care 2012;35:1578-84.

88. Selvin E, Steffes M, Zhu H, et al. Glycated hemoglobin, diabetes, and cardiovascular risk in nondiabetic adults. N Engl J Med 2010;362:800-11.

89. Borg R, Vistisen D, Witte DR, et al. Comparing risk profiles of individuals diagnosed with diabetes by OGTT and HbA1c The Danish Inter99 study. Diabet Med 2010;27:906-10.

90. International Epidemiological Association. Dictionary of Epidemiology. New York, NY: Oxford University Press; 2008. 